\title{
Potent antitumor activity of cepharanthine against triple-negative breast cancer spheroids compared with tetrandrine
}

\author{
ANNA KIYOMI $^{1}$, RISAKO MIYAKAWA ${ }^{1}$, JURI MATSUMOTO ${ }^{1}$, KYOUSUKE YAMAZAKI ${ }^{1}$, \\ SHINOBU IMAI $^{1}$, BO YUAN ${ }^{2}$, TOSHIHIKO HIRANO ${ }^{3}$ and MUNETOSHI SUGIURA ${ }^{1}$ \\ ${ }^{1}$ Department of Drug Safety and Risk Management, School of Pharmacy, Tokyo University of Pharmacy \\ and Life Sciences, Hachioji, Tokyo 192-0392; ${ }^{2}$ Laboratory of Pharmacology, School of Pharmacy, \\ Josai University, Sakado, Saitama 350-0295; ${ }^{3}$ Department of Clinical Pharmacology, School of Pharmacy, \\ Tokyo University of Pharmacy and Life Sciences, Hachioji, Tokyo 192-0392, Japan
}

Received April 22, 2020; Accepted September 7, 2020

DOI: $10.3892 / \mathrm{ol} .2020 .12191$

\begin{abstract}
Cepharanthine (CEP) is a bis-bynzelisoquinoline alkaloid from the same class as the anticancer agent tetrandrine (TET). However, the effects of CEP against breast cancer have not been extensively studied, despite its long therapeutic history with low toxicity against other types of cancer. 3D culture systems more accurately mimic the human body and address the limitations of determining drug effectiveness compared with $2 \mathrm{D}$ culture systems. In the present study, the antitumor activities of TET and CEP were compared in 3D culture systems in triple-negative breast cancer (TNBC) MDA-MB-231 and estrogen receptor-positive breast cancer MCF-7 cell lines. Cell viability, apoptosis and cytotoxicity assays were performed to determine the total number of live or dead cells, the $\mathrm{IC}_{50}$ values, the number of apoptotic cells and spheroid roundness. Viability suppression of MDA-MB-231 cells was significantly greater with both TET and CEP compared with that of MCF-7 cells, and the roundness of MDA-MB-231 spheroids treated with CEP was decreased significantly compared with that of spheroid treated with TET. Cytoplasmic shrinkage in each cell line significantly increased with the treatment of TET compared with the control; however, this effect was stronger with CEP. The ratio of dead/live cells in each cell line treated with TET and CEP increased in a dose-dependent manner. Overall, the
\end{abstract}

Correspondence to: Dr Anna Kiyomi, Department of Drug Safety and Risk Management, School of Pharmacy, Tokyo University of Pharmacy and Life Sciences, 1432-1 Horinouchi, Hachioji, Tokyo 192-0392, Japan

E-mail: akiyomi@toyaku.ac.jp

Abbreviations: CEP, cepharanthine; TET, tetrandrine; ER, estrogen receptor; PgR, progesterone receptor; TNBC, triple-negative breast cancer; ULA, ultra-low adherence; CCK-8, Cell Counting Kit-8

Key words: antitumor, breast cancer, CEP, spheroid, 3D culture, TET present study demonstrated that CEP had greater cell toxicity in 3D spheroids of breast cancer cells compared with TET, suggesting that CEP may have a stronger antitumor activity on TNBC spheroids compared with TET.

\section{Introduction}

Breast cancer is the most common cancer in women worldwide (1-3) and is classified by subtype based on the expression of estrogen receptor (ER), progesterone receptor $(\mathrm{PgR})$ and HER2. Luminal A and B breast cancer is hormone receptor-positive $\left(\mathrm{ER}^{+}\right.$and/or $\left.\mathrm{PgR}^{+}\right)$and accounts for $\sim 70 \%$ of all patients with breast cancer (4). However, triple-negative breast cancer (TNBC), which lacks expression of all receptors (ER', $\mathrm{PgR}^{-}$and HER2), is the most difficult malignancy to treat because there are no specific targets (5). The treatment of TNBC generally requires a highly toxic chemotherapeutic regimen that includes anthracyclines or taxanes $(6,7)$. Although a number of patients may respond well during the initial stages of chemotherapy, there are numerous cases where patients develop resistance to these chemotherapeutic agents over time (8).

Molecules derived from natural products have been explored as novel chemotherapeutic agents because of their high affinity and selectiveness to physiologically relevant receptors $(9,10)$. Tetrandrine (TET) is a bis-benzylisoquinoline alkaloid that has been extracted from the traditional Chinese herb Stephania tetrandra (Fig. 1) (11). TET possesses a notable antitumor activity in numerous types of cancer, including gastric, lung, liver and colorectal cancer, both in vitro and in vivo $(12,13)$. The mechanisms of action of TET are associated with multiple factors, such as modulating molecular signaling pathways (14), inducing cancer cell apoptosis (15), promoting cell cycle arrest (16) and increasing cell autophagy (17). Although TET has been approved in China for some types of cancer, such as acute myelogenous leukemia and advanced non-small cell lung cancer $(18,19)$, it has not been yet approved in Japan as an antitumor drug for patients with cancer. Cepharanthine (CEP), a TET analog extracted from traditional Japanese herbs, Stephania cephalantha, has been approved in Japan for the treatment of alopecia areata 
and leukopenia caused by radiation therapy (Fig. 1) (20). However, less research on CEP as an anticancer agent has been conducted $(21,22)$. Therefore, it is imperative to evaluate the effectiveness of CEP for cancer treatment as an alternative drug in Japan compared with TET in China.

In $2 \mathrm{D}$ cell culture, cells are grown on a flat surface as a monolayer, and this culture method is widely used in numerous biological studies. However, all cells in the human body are both morphologically and functionally different from flat, planar cells $(23,24)$. To apply CEP towards clinical use, it is important to consider the cell culture techniques that best mimic the intricate in vivo cell environment. The $3 \mathrm{D}$ cell culture method has been demonstrated to mimic the in vivo environment more appropriately compared with $2 \mathrm{D}$ cell cultures $(25,26)$. There are a variety of $3 \mathrm{D}$ methods that require special reagents and culture techniques, such as the spinner cultivation technique (27), alginate (28), agarose (29), soft agarose, Matrige ${ }^{\circledR}(30)$ and collagen matrix gel (31) containing cytotoxic enzymes. However, the ultra-low adherence (ULA) method, which is a type of scaffold-free $3 \mathrm{D}$ cell culture method, is very simple and convenient to use (32). ULA plates are specially precoated with a hydrogel to enable globose spheroids that are structured by cells (33). The hydrogel coating is stable, displays no cytotoxicity, has no biological activity and does not dissolve (33). In addition, the cells seeded in these plates float in the medium and start forming spheroids independently (34). The shape of the well is round and promotes the formation of a single spheroid per well, located centrally; additionally, cells can be imaged easily since there is only one spheroid per well (35).

The aim of the present study was to evaluate and compare the antitumor activities of TET and CEP on the $\mathrm{ER}^{+}$breast cancer MCF-7 cell line and the TNBC MDA-MB-231 cell line, using a $3 \mathrm{D}$ culture system compared with a $2 \mathrm{D}$ culture system.

\section{Materials and methods}

Materials and drug preparation. TET and CEP were purchased from Cayman Chemical and Kakenshoyaku Co., Ltd., respectively. DMSO and Triton X-100 were obtained from FUJIFILM Wako Pure Chemical Corporation. FBS was purchased from Sigma-Aldrich (Merck KGaA). Minimum essential medium (MEM)- $\alpha$, penicillin-streptomycin $(10,000 \mathrm{U} / \mathrm{ml}$ penicillin and $10,000 \mu \mathrm{g} / \mathrm{ml}$ streptomycin), 10X PBS, trypan blue and TrypLE Express were purchased from Gibco (Thermo Fisher Scientific, Inc.). The Cell Counting Kit-8 (CCK-8), calcein-AM, Hoechst 33342 and propidium iodide (PI) were obtained from Dojindo Molecular Technologies, Inc. TET and CEP solutions were prepared by first dissolving them in DMSO and then diluting them into the media to a final concentration of $0.1 \%$. They were stored at $-20^{\circ} \mathrm{C}$ until further use.

Cell lines. The human breast cancer MDA-MB-231 and MCF-7 cell lines were purchased from RIKEN BioResource Center and the American Type Culture Collection, respectively. MCF-7 and MDA-MB-231 cells were maintained in MEM- $\alpha$ supplemented with $10 \% \mathrm{FBS}, 100 \mathrm{U} / \mathrm{ml}$ penicillin and $100 \mu \mathrm{g} / \mathrm{ml}$ streptomycin at $37^{\circ} \mathrm{C}$ in a humidified atmosphere with $5 \% \mathrm{CO}_{2}$.

\section{Cell culture and drug treatment}

$2 D$ culture. MDA-MB-231 and MCF-7 cells were seeded in 96-well plates (IWAKI \& Co., Ltd.) or OptiPlates (PerkinElmer,Inc.) ata density of $1 \times 10^{5}, 2.5 \times 10^{5}$ or $5 \times 10^{5} \mathrm{cells} / \mathrm{ml}$, and in 24-well plates at a density of $2 \times 10^{5}$ cells $/ \mathrm{ml}$ depending on the experiments and cultivated for $24 \mathrm{~h}$ at $37^{\circ} \mathrm{C}$ in a humidified atmosphere with $5 \% \mathrm{CO}_{2}$.

$3 D$ culture. MDA-MB-231 and MCF-7 cells were seeded in 96-well CellCarrier Spheroid ULA plates (PerkinElmer, Inc.) at a density of $1 \times 10^{5}$ or $2 \times 10^{5}$ cells $/ \mathrm{ml}$ depending on the experiments and cultivated for $24 \mathrm{~h}$ at $37^{\circ} \mathrm{C}$ in a humidified atmosphere containing $5 \% \mathrm{CO}_{2}$. The seeding density had to be below complete confluency and was determined based on the manufacturer's maximum suggested number of $4 \times 10^{4}$ cells/well for $100 \%$ confluency.

Drug treatment. Vehicle for controls (cell culture medium) and different concentrations of TET or CEP were subsequently added into the corresponding wells and adjusted to final drug concentrations of $0,0.1,0.3,1,3,4,6,8,10,30$ and $100 \mu \mathrm{g} / \mathrm{ml}$. These concentrations were selected based on a previous report demonstrating that CEP and TET caused apoptosis in glucocorticoid-resistant human leukemia Jurkat $T$ cells after $72 \mathrm{~h}$ of treatment (36). MDA-MB-231 and MCF-7 cells were allowed to grow for $72 \mathrm{~h}$ at $37^{\circ} \mathrm{C}$ in the presence of the drug. Long-term treatment times are traditionally used for determining the efficacy of anticancer drugs, and therefore the 72-h time point was selected to ensure sufficient exposure to CEP and TET as previously described $(35,37)$. Cell treatment was followed by a cell viability assay, cytotoxicity assay and apoptosis detection.

Determination of cell viability inhibition. MDA-MB-231 and MCF-7 cells $\left(1 \times 10^{5}, 2.5 \times 10^{5}\right.$ or $5 \times 10^{5}$ cells $\left./ \mathrm{ml}\right)$ were seeded into 96-well flat bottom plates, and then TET or CEP were added at various concentrations as aforementioned. The plates were subsequently incubated at $37^{\circ} \mathrm{C}$ with $5 \% \mathrm{CO}_{2}$ for $72 \mathrm{~h}$. After incubation, $10 \mu \mathrm{l}$ CCK-8 reagent was added into each well according to the manufacturer's protocol, followed by an additional incubation for $3 \mathrm{~h}$ at $37^{\circ} \mathrm{C}$. The optical density (OD) of each well was measured using a Corona MT P-32 micro-plate reader (Corona Electric Co., Ltd.) at $450 \mathrm{~nm}$. Cell viability was calculated according to the following equation: Cell viability rate $=(\mathrm{OD}$ sample value-OD blank value $) /(\mathrm{OD}$ control value-OD blank value) x 100 . The half-maximal inhibitory concentration $\left(\mathrm{IC}_{50}\right)$ was calculated using GraphPad Prism 8.0 (GraphPad Software, Inc.), based on the cell viability of the untreated cells (control).

Spheroid area and roundness evaluation. The microscopic images of the 2D- and 3D-cultured cells or spheroids seeded as $1 \times 10^{5}$ cells/ml were taken using an Operetta CLS high-content analysis system (PerkinElmer, Inc.) and the cell morphological structure of MDA-MB-231 and MCF-7 cells in both 2D and 3D cultures were analyzed. The spheroid area and roundness were observed $72 \mathrm{~h}$ after drug treatment for 3D cultures using the same system. A series of images were recorded and examined using $x 5$ magnification. Spheroid area and roundness were measured and analyzed using the Harmony 4.5 software (PerkinElmer, Inc.). 
A

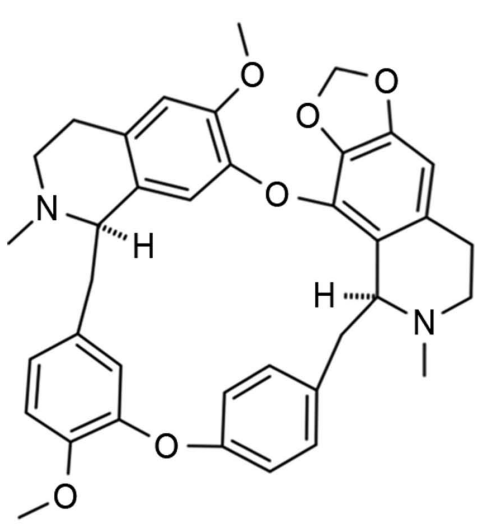

B<smiles>COc1ccc(C[C@@H]2c3c(cc(OC)c(OC)c3Oc3cc4c(cc3OC)CCN(C)[C@H]4Cc3ccc(Oc4ccc(OC)c(OC)c4)cc3)CCN2C)cc1</smiles>

Figure 1. Chemical structures of (A) cepharanthine and (B) tetrandrine.

Cell cytotoxicity. The cytoplasm and nuclei of the dead cells were evaluated in order to determine the cause of cell toxicity. The supernatant of each well was removed, and the cells were washed twice with sterile PBS after $72 \mathrm{~h}$ of drug treatment. MDA-MB-231 and MCF-7 2D-cultured cells $\left(1 \times 10^{5}\right.$ cells $\left./ \mathrm{ml}\right)$ were stained with $4 \mu \mathrm{M}$ calcein-AM, $10 \mu \mathrm{M}$ of Hoechst 33342 and $4 \mu \mathrm{M}$ PI for $15 \mathrm{~min}$ at room temperature in the dark. The spheroids were only stained with calcein-AM and PI in order to detect cell viability. The Harmony 4.5 software was used to detect and determine the fluorescence intensity using the following wavelengths: Calcein-AM excitation, $496 \mathrm{~nm}$ and emission, $517 \mathrm{~nm}$; Hoechst 33342 excitation, $343 \mathrm{~nm}$ and emission, $483 \mathrm{~nm}$; and PI excitation, $560 \mathrm{~nm}$ and emission, $595 \mathrm{~nm}$.

Assessment of apoptosis. Apoptotic cell rates in MDA-MB-231 and MCF-7 cells were analyzed using an Annexin V-FITC apoptosis detection kit (BD Biosciences). Both cell lines adjusted to $2 \times 10^{5}$ cells $/ \mathrm{ml}$ were seeded in 24 -well plates for the 2D culture or in 96-well CellCarrier Spheroid ULA plates for the 3D culture, and treated by serial dilution with TET or CEP (final concentrations: 0, 1, 3, 10 and $30 \mu \mathrm{g} / \mathrm{ml}$ ) followed by an additional $72 \mathrm{~h}$ of incubation at $37^{\circ} \mathrm{C}$. Subsequently, the staining procedure was performed according to the manufacturer's protocol. The duration of staining with Annexin V-FITC (excitation and emission wavelengths at 485 and $535 \mathrm{~nm}$, respectively) and PI (excitation and emission wavelengths at 560 and $595 \mathrm{~nm}$, respectively) was $15 \mathrm{~min}$ at room temperature in the dark. Dissociation of the spheroids into single cells was performed by resuspending the spheroids in TrypLE Express. A total of $1 \times 10^{4}$ cells was analyzed via flow cytometry (FACSCanto and FACSDiva software v6.0; both BD Biosciences). The cells were subsequently assessed for viable (Annexin $\mathrm{V}^{-} / \mathrm{PI}^{-}$), early apoptotic (Annexin $\mathrm{V}^{+} / \mathrm{PI}^{-}$), late apoptotic (Annexin $\mathrm{V}^{+} / \mathrm{PI}^{+}$) and necrotic (Annexin $\mathrm{V}^{-} / \mathrm{PI}^{+}$) cells. Triton-X100 was used for detecting $\mathrm{PI}^{+}$control cells.

Statistical analysis. All experiments were repeated $\geq 3$ times and the data are presented as the mean \pm SD. Cell viability of 2D MDA-MB-231 or MCF-7 monolayer cells treated with TET or CEP cultured at different cell densities was analyzed using one-way ANOVA followed by Tukey's multiple comparisons test. The comparison of the cell viability between 2D-cultured MCF-7 cells treated with TET and CEP versus MDA-MB-231 cells was analyzed using the Mann-Whitney U test, while the comparison of $\mathrm{IC}_{50}$ values of CEP or TET between $2 \mathrm{D}$ monolayer MDA-MB-231 and MCF-7 cells was analyzed via one-way ANOVA with a post-hoc Sidak's multiple comparisons test. A one-way ANOVA followed by Dunnett's multiple comparisons test was used for the comparisons of the intensity of calcein, Hoechst 33342 and PI, the spheroid area and roundness, and the percentages of viable, early apoptotic and late apoptotic cells of 2D- and 3D-cultured MDA-MB-231 and MCF-7 cells treated with CEP or TET compared with control cells. $\mathrm{P}<0.05$ was considered to indicate a statistically significant difference. All statistical analyses were performed using GraphPad Prism 8.0 (GraphPad Software, Inc.).

\section{Results}

Cell viability and $I_{50}$ values of TET and CEP. The cell viability and $\mathrm{IC}_{50}$ values of TET and CEP were determined in 2D monolayers of MCF-7 and MDA-MB-231 cells using the CCK-8 assay. Cell viability decreased with TET or CEP treatment in a dose-dependent manner (Fig. 2). MDA-MB-231 cells (Fig. 2C and D) were more affected by the cytotoxic effects of TET and CEP compared with MCF-7 cells (Fig. 2A and B). Using a concentration of $>3 \mu \mathrm{g} / \mathrm{ml}$ CEP suppressed the viability of MDA-MB-231 cells significantly compared with the control $(\mathrm{P}<0.05$; Fig. 2D). The viability of MDA-MB-231 cells was significantly suppressed using $0.1 \mu \mathrm{g} / \mathrm{ml}$ and high doses of CEP compared with that of MCF-7 cells (Fig. 3A and B). Furthermore, the viability of MDA-MB-231 cells was significantly suppressed compared with that of MCF-7 cells when high doses of TET were used (Fig. 3C and D).

The $\mathrm{IC}_{50}$ values of TET and CEP required to suppress the cell viability of each cell line were calculated (Table I). MDA-MB-231 cells were more sensitive to CEP and TET compared with $\mathrm{MCF}-7$ cells. The $\mathrm{IC}_{50}$ value of $\mathrm{CEP}$ for MDA-MB-231 cells was 7 times lower than that for MCF-7 cells at $5 \times 10^{5}$ cells $/ \mathrm{ml}$. Additionally, the $\mathrm{IC}_{50}$ value of TET for MDA-MB-231 cells was $>8$ times lower than that for MCF-7 cells at $5 \times 10^{5}$ cells $/ \mathrm{ml}$. Therefore, CEP affected the cell 

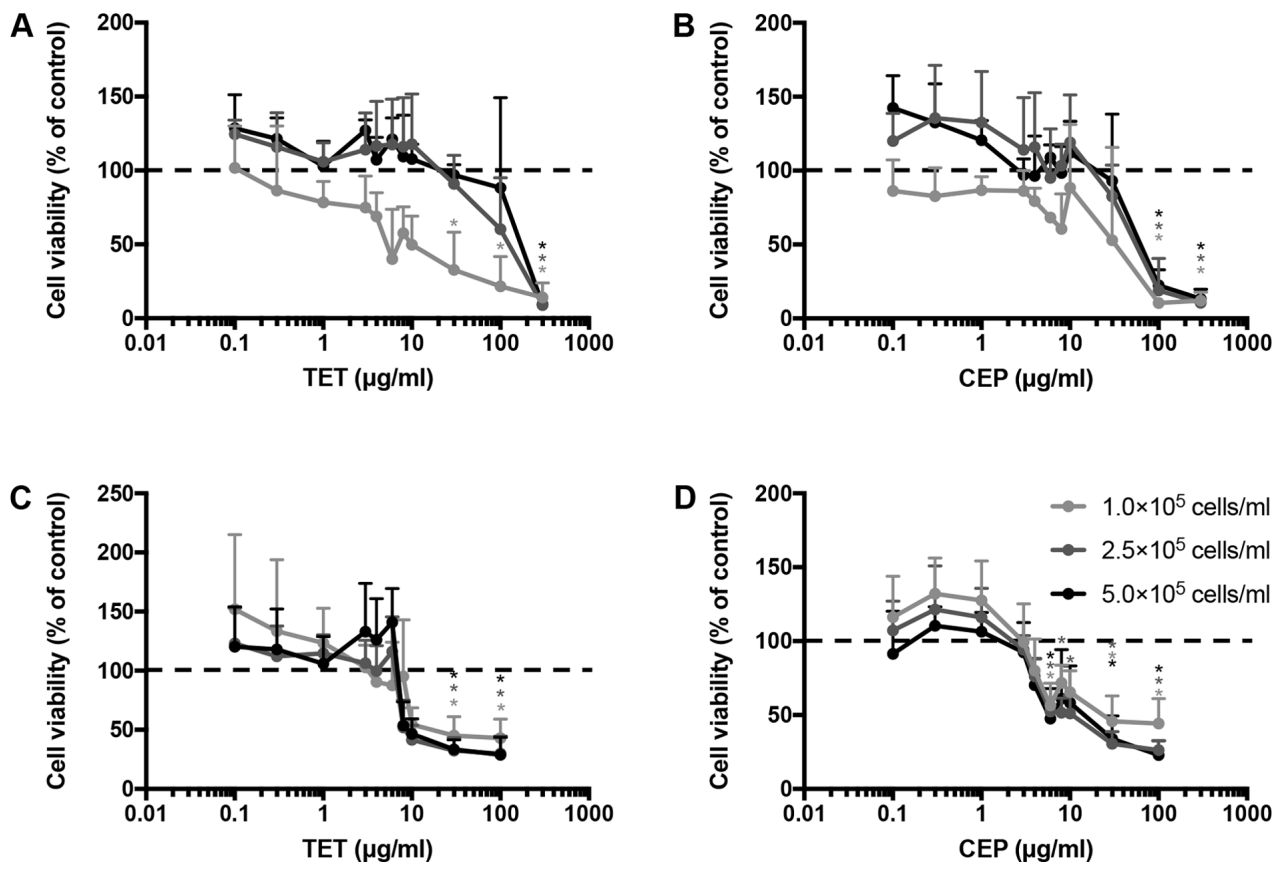

Figure 2. Cell viability of 2D MDA-MB-231 or MCF-7 monolayer cells treated with TET or CEP cultured at different cell numbers. Cytotoxic effects of (A) TET and (B) CEP on 2D monolayer breast cancer MCF-7 cells cultured at different cell numbers. Cytotoxic effects of (C) TET and (D) CEP on 2D monolayer breast cancer MDA-MB-231 cells at different cell numbers. Cell viability was determined using the Cell Counting Kit- 8 assay after treatment with various concentrations $(0-100 \mu \mathrm{g} / \mathrm{ml})$ of TET and CEP. Relative cell viability was calculated as the ratio of the absorbance at $450 \mathrm{~nm}$ of each treatment group against those of the corresponding untreated control group. Data are shown as the mean \pm SD of $>3$ independent experiments and were analyzed via one-way ANOVA followed by Tukey's multiple comparisons test. "P<0.05 vs. control (untreated) group, represented as $100 \%$ of the y-axis (dotted line). CEP, cepharanthine; TET, tetrandrine.

A

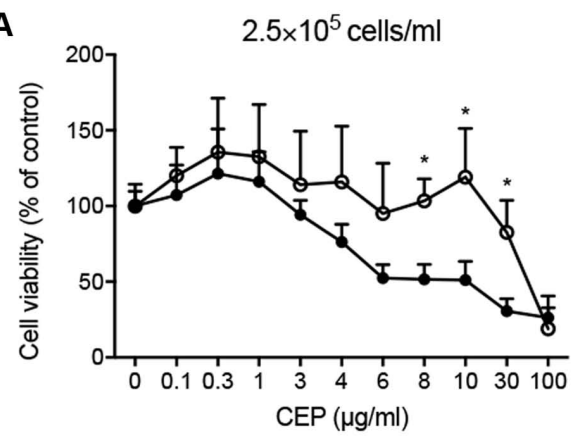

C

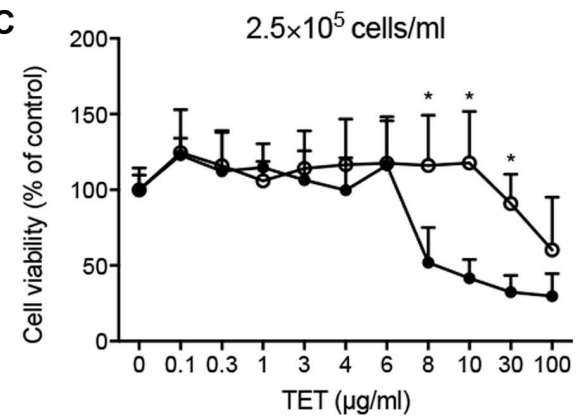

B
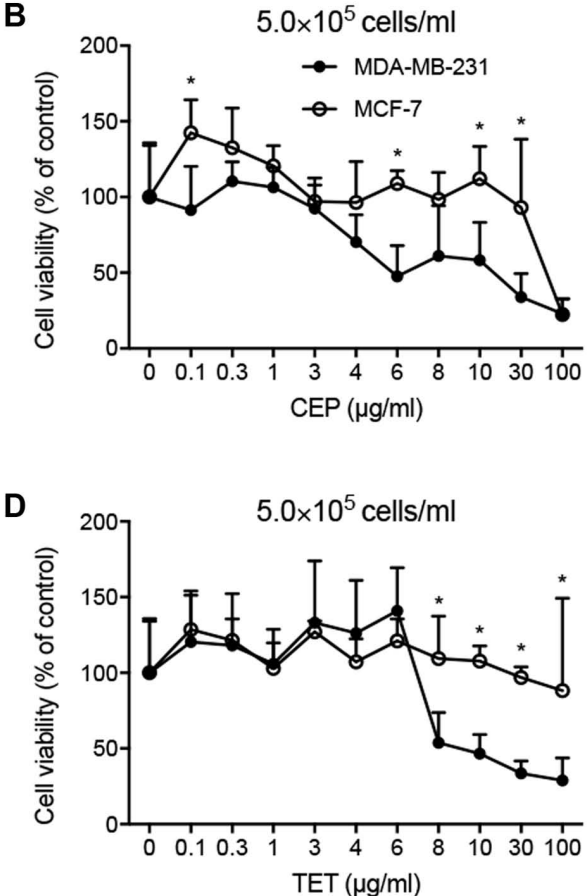

Figure 3. Comparison of the cell viability between 2D-cultured MDA-MB-231 and MCF-7 cells treated with TET and CEP. Cell viability in 2D monolayer MDA-MB-231 and MCF-7 cells treated with CEP at (A) $2.5 \times 10^{5}$ cells $/ \mathrm{ml}$ and (B) $5.0 \times 10^{5}$ cells $/ \mathrm{ml}$, or TET at (C) $2.5 \times 10^{5}$ cells $/ \mathrm{ml}$ and (D) $5.0 \times 10^{5}$ cells $/ \mathrm{ml}$ detected via Cell Counting Kit- 8 assay. Data are shown as the mean \pm SD of $>3$ independent experiments and were analyzed using the Mann-Whitney U test. ${ }^{*} \mathrm{P}<0.05$ vs. MDA-MB-231 cells. CEP, cepharanthine; TET, tetrandrine.

viability of MDA-MB-231 cells at lower concentrations than that of MCF-7 cells. There were significant differences in the $\mathrm{IC}_{50}$ values of CEP between MDA-MB-231 and MCF-7 cells at densities of $2.5 \times 10^{5}$ and $5 \times 10^{5}$ cells $/ \mathrm{ml}$, and in the $\mathrm{IC}_{50}$ values of TET between MDA-MB-231 and MCF-7 cells at a density of $5 \times 10^{5}$ cells $/ \mathrm{ml}(\mathrm{P}<0.05$; Fig. 4). 
Table I. Mean $\mathrm{IC}_{50}$ values of CEP and TET on the cell viability of 2D monolayer MDA-MB-231 and MCF-7 cells.

\begin{tabular}{llrrr}
\hline Drug & Cell line & $1 \times 10^{5}$ cells $/ \mathrm{ml}$ & $2.5 \times 10^{5}$ cells $/ \mathrm{ml}$ & $5 \times 10^{5}$ cells $/ \mathrm{ml}$ \\
\hline CEP & MDA-MB-231 & 3.8 & $5.4^{\mathrm{a}}$ & $8.6^{\mathrm{a}}$ \\
& MCF-7 & 17.6 & 35.6 & 60.4 \\
TET & MDA-MB-231 & 6.4 & 7.6 & $9.6^{\mathrm{a}}$ \\
& MCF-7 & 13.5 & 26 & 84.7 \\
\hline
\end{tabular}

$\mathrm{IC}_{50}$ values were calculated based on the sigmoidal curve of the cell viability using GraphPad Prism v8.0. The results are shown as the mean $(\mu \mathrm{g} / \mathrm{ml})$ of $>3$ independent experiments. ${ }^{a} \mathrm{P}<0.05$ vs. the mean $\mathrm{IC}_{50}$ value of CEP or TET on MCF-7 cells analyzed via one-way ANOVA with a post-hoc Sidak's multiple comparisons test.

A

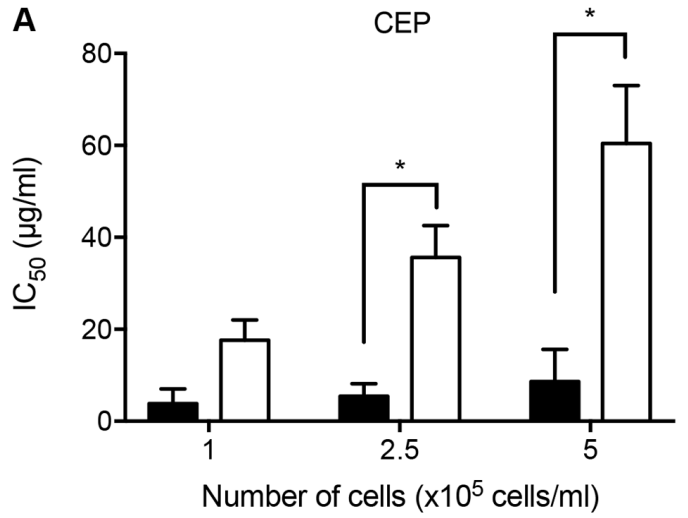

B

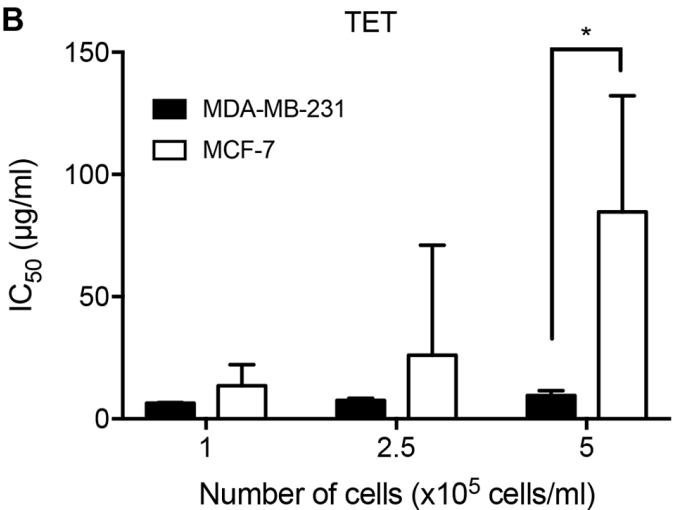

Figure 4. Comparison of $\mathrm{IC}_{50}$ values of CEP or TET between 2D monolayer MDA-MB-231 and MCF-7 cells cultured at different cell numbers. Cells were cultured at cell numbers of $1.0,2.5$ or $5.0 \times 10^{5}$ cells $/ \mathrm{ml}$ in the presence of (A) CEP or (B) TET, and the IC $\mathrm{C}_{50}$ values were evaluated. The IC ${ }_{50}$ values of $\mathrm{CEP}_{\text {and }}$ TET on MDA-MB-231 cells were lower than those of MCF-7 cells. Data are shown as the mean \pm SD of $>3$ independent experiments. ${ }^{*}<0.05$ analyzed via one-way ANOVA followed by Sidak's multiple comparisons test. CEP, cepharanthine; TET, tetrandrine.

A

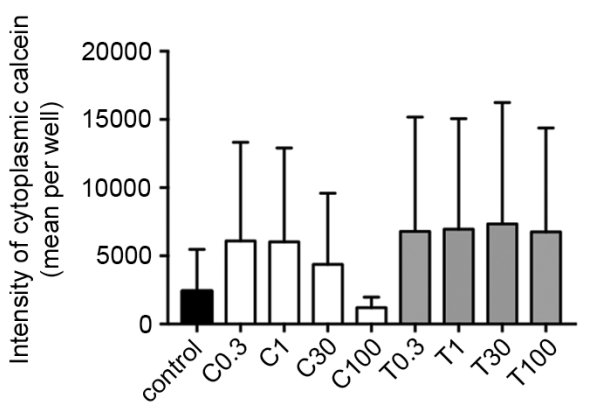

B

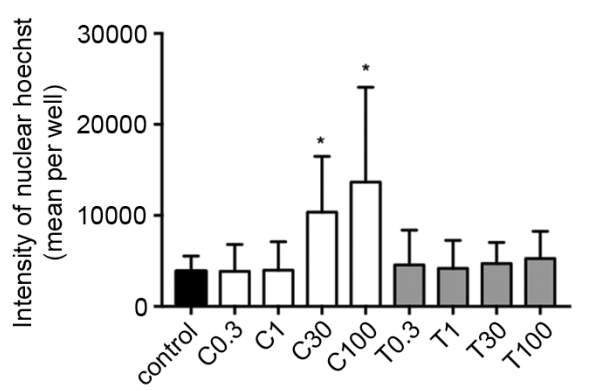

C

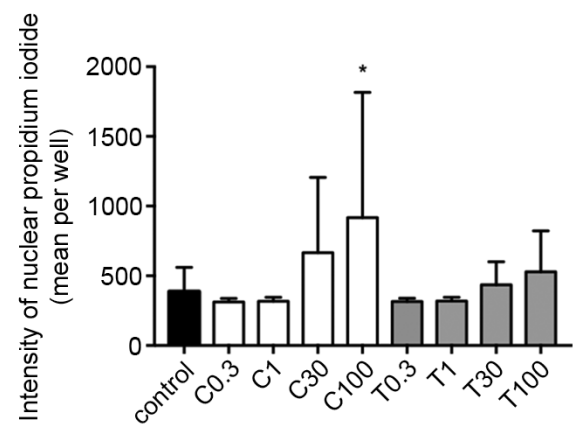

Figure 5. Fluorescence intensities of calcein, Hoechst and propidium iodide in 2D MDA-MB-231 monolayer cell cultures treated with different concentrations of CEP or TET. Fluorescence intensities of (A) calcein (cytoplasm), (B) Hoechst (chromatin) and (C) propidium iodide (dead cells) were detected after 15 min of incubation using an Operetta CLS (PerkinElmer, Inc.). Data are shown as the mean \pm SD of 4 independent experiments. * $<<0.05$ vs. control analyzed via one-way ANOVA and Dunnett's multiple comparisons test. C/CEP, cepharanthine; T/TET, tetrandrine.

Microscopic analyses on cell cytotoxicity. To further understand cell cytotoxicity of CEP and TET on breast cancer cells or spheroids, 2D monolayer and 3D spheroids were stained with calcein, Hoechst and PI, and the fluorescence intensity was measured to identify changes in the cytoplasm, nuclei and dead cells, respectively.

The calcein fluorescence intensity in the cytoplasm of 2D-cultured MDA-MB-231 cells was decreased in a concentration-dependent manner by CEP, but not by TET (Fig. 5A).
Additionally, the fluorescence intensities of Hoechst and PI were significantly increased using $100 \mu \mathrm{g} / \mathrm{ml} \mathrm{CEP,} \mathrm{but} \mathrm{not}$ by TET $(\mathrm{P}<0.05$; Fig. $5 \mathrm{~B}$ and $\mathrm{C})$. These effects were more strongly observed in 2D monolayer cultures of MCF-7 cells compared with those in MDA-MB-231 cells. The fluorescence intensity in the cytoplasm of MCF-7 cells was significantly decreased using $100 \mu \mathrm{g} / \mathrm{ml}$ of CEP compared with that in the control group $(\mathrm{P}<0.05$; Fig. 6A). Conversely, the intensity in the nucleus of Hoechst and PI in MCF-7 cells was significantly 
A

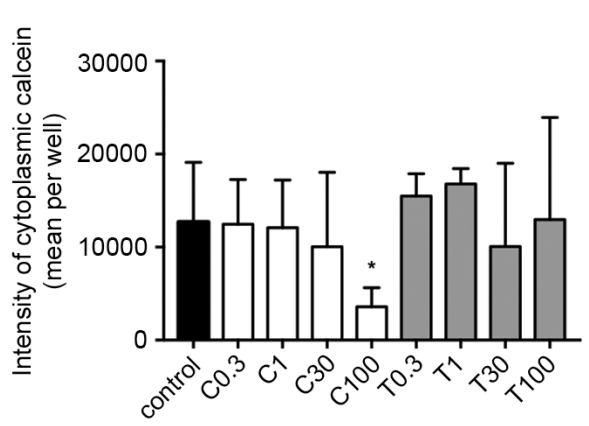

B

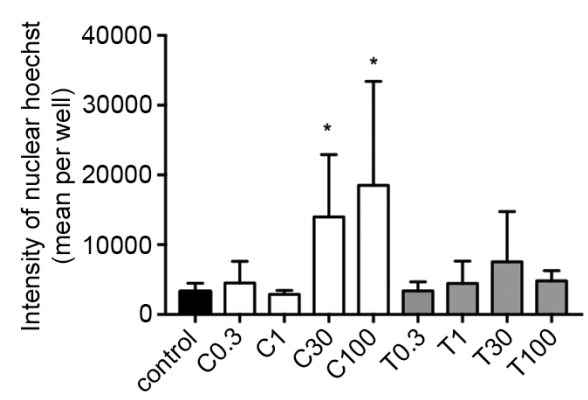

C

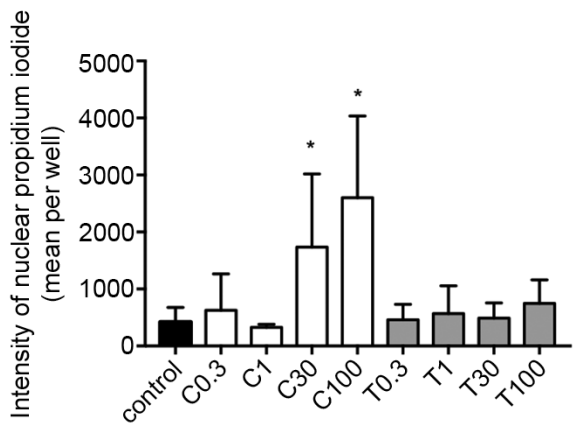

Figure 6. Fluorescence intensities of calcein, Hoechst and propidium iodide in 2D MCF-7 monolayer cells treated with different concentrations of CEP or TET. Fluorescence intensities of (A) calcein (cytoplasm), (B) Hoechst (chromatin) and (C) propidium iodide (dead cells) were detected after 15 min of incubation using an Operetta CLS (PerkinElmer, Inc.). Data are shown as the mean \pm SD of 4 independent experiments. ${ }^{*} \mathrm{P}<0.05$ vs. control analyzed via one-way ANOVA and Dunnett's multiple comparisons test. C/CEP, cepharanthine; T/TET, tetrandrine.

Calcein

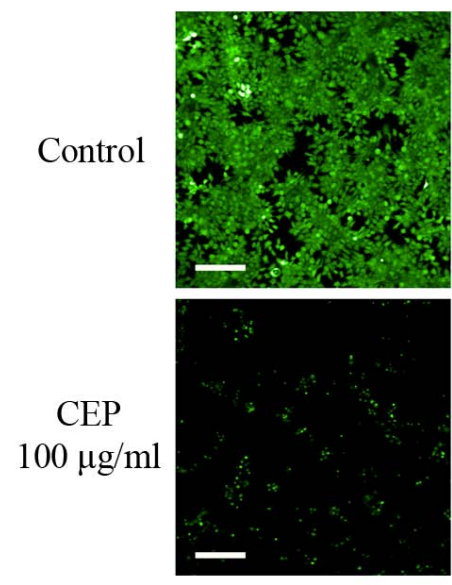

Hoechst
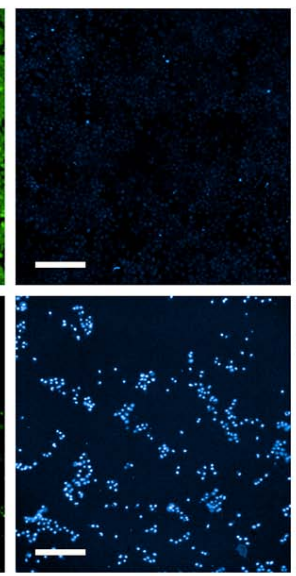

PI
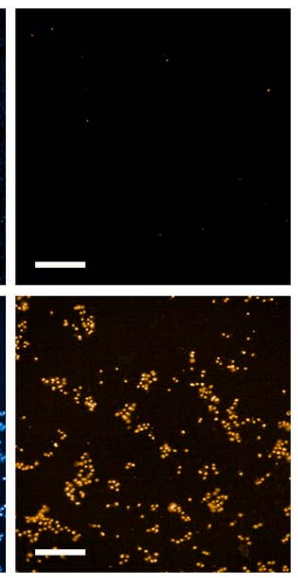

Figure 7. Photomicrographs of CEP-treated 2D MCF-7 monolayer cells stained with calcein, Hoechst or PI. MCF-7 cells were treated with $100 \mu$ g/ml CEP and stained with calcein green, Hoechst blue or PI red, which represent the cytoplasm, chromatin (nuclei) or dead cells, respectively. CEP induced chromatin aggregation and cell death. Scale bar, $200 \mu \mathrm{m}$. CEP, cepharanthine; PI, propidium iodide.

increased when using $>30 \mu \mathrm{g} / \mathrm{ml}$ of CEP compared with that in the control group, indicating the induction of stronger cell death compared with the control group in these cells $(\mathrm{P}<0.05$; Fig. 6B and C). However, TET did not have any significant effects on the three intensities (Fig. 6). Microscopic images of 2D-cultured MCF-7 cells treated with $100 \mu \mathrm{g} / \mathrm{ml}$ of CEP revealed no cytoplasm intensity and increased intensity of the nucleus and dead cells compared with in the control group (Fig. 7). The fluorescence images of all cells with all treatment concentrations are shown in Fig. S1.

In MDA-MB-231 (Fig. 8) and MCF-7 (Fig. 9) spheroids, CEP significantly decreased the calcein intensity in a dose-dependent manner ( $\mathrm{P}<0.05$; Figs. $8 \mathrm{~A}$ and $9 \mathrm{~A})$. Although the cytoplasm intensity in MDA-MB-231 cells was significantly decreased using $100 \mu \mathrm{g} / \mathrm{ml}$ TET, TET had a lower effect on the cytoplasm intensity in spheroids of both cell lines. Conversely, TET significantly increased the PI level in both cell lines $(\mathrm{P}<0.05$; Figs. $8 \mathrm{~B}$ and $9 \mathrm{~B})$ when used at 30 and $100 \mu \mathrm{g} / \mathrm{ml}$, compared with in the control group. Additionally, CEP significantly increased the number of dead cells only in 3D MCF-7 spheroids ( $\mathrm{P}<0.05$; Fig. 9B) at 30 and $100 \mu \mathrm{g} / \mathrm{ml}$, but not in 3D MDA-MB-231 spheroids (Fig. 8B). The microscopic images of the 3D-cultured MCF-7 spheroids revealed that $100 \mu \mathrm{g} / \mathrm{ml}$ of CEP decreased the intensity of calcein and increased the intensity of PI compared with that in control spheroids (Fig. 10). The fluorescence images of all cells with all treatment concentrations are shown in Fig. S2.

In addition to the calcein and PI staining, the spheroid area and roundness of 3D spheroids were calculated. The 'roundness' parameter was defined as a measure of how close the shape of the 2D spheroid was to a circle (the gross feature of the shape). The spheroid areas in both MDA-MB-231 and MCF-7 cells did not significantly change from the control depending on treatment, except when using $30 \mu \mathrm{g} / \mathrm{ml}$ TET, which significantly decreased the spheroid area of MCF-7 cells (Figs. 8C and 9C). The roundness tended to decrease with higher concentrations of CEP and TET (Figs. 8D and 9D), although the roundness of MDA-MB-231 spheroids treated with $1 \mu \mathrm{g} / \mathrm{ml}$ TET was increased compared with the control. Using 30 and $100 \mu \mathrm{g} / \mathrm{ml}$ of CEP significantly decreased the roundness of MDA-MB-231 spheroids $(\mathrm{P}<0.05$; Fig. 8D). 
A

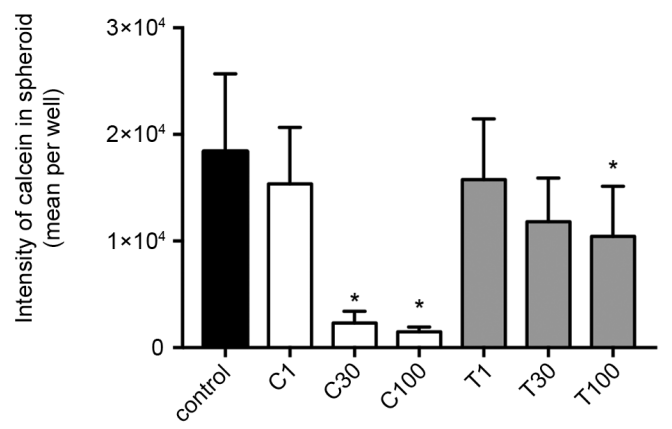

C

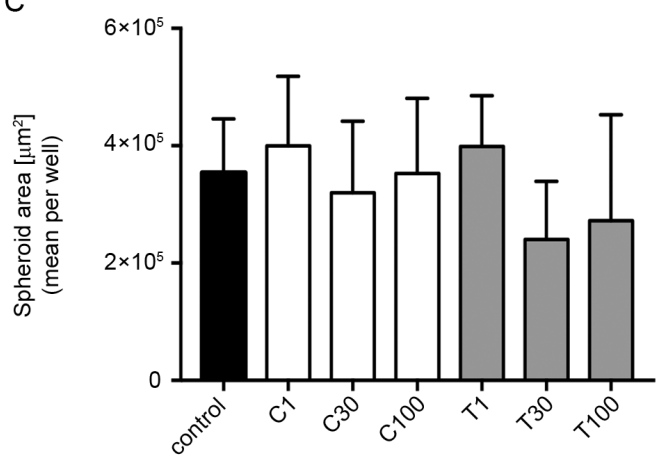

$\mathrm{B}$

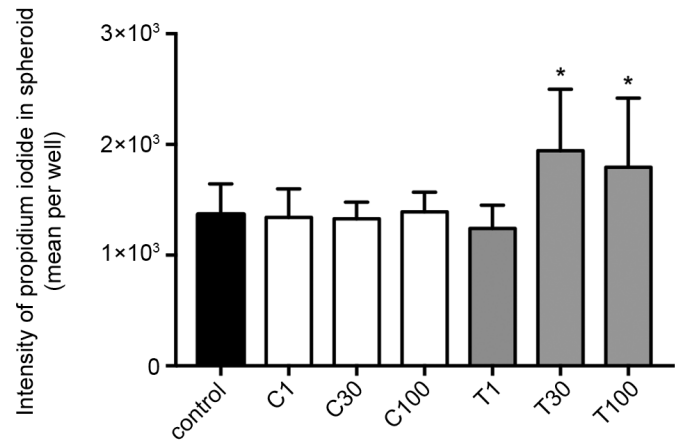

D

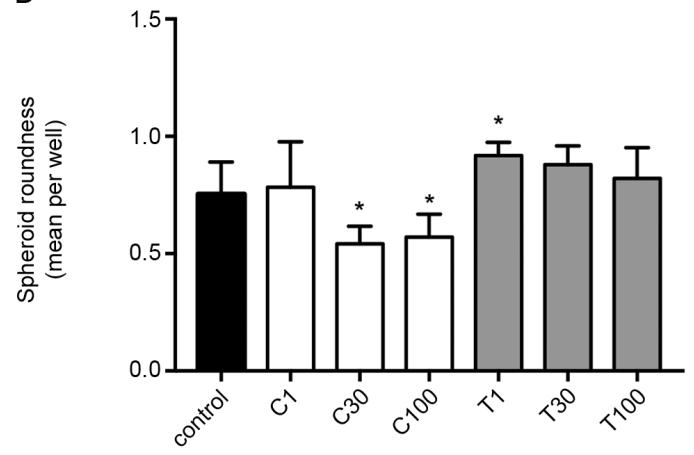

Figure 8. Fluorescence intensities and morphological examinations of spheroids of 3D MDA-MB-231 cells treated with different concentrations of CEP or TET. Fluorescence intensity of (A) calcein and (B) propidium iodide in spheroids. (C) Spheroid area and (D) spheroid roundness of 3D MDA-MB-231 cells treated with CEP or TET. The intensity of calcein (cytoplasm) and propidium iodide (dead cells) fluorescence were detected after 15 min of incubation using an Operetta CLS (PerkinElmer, Inc.). The spheroid area and the roundness were calculated using the same instrument. The data are shown as the mean $+\mathrm{SD}$ of 4 independent experiments. A roundness value of 1 corresponds to complete roundness, and lower values indicate the deformation of the spheroid. " $\mathrm{P}<0.05$ vs. control analyzed via one-way ANOVA and Dunnett's multiple comparisons test. C/CEP, cepharanthine; T/TET, tetrandrine.
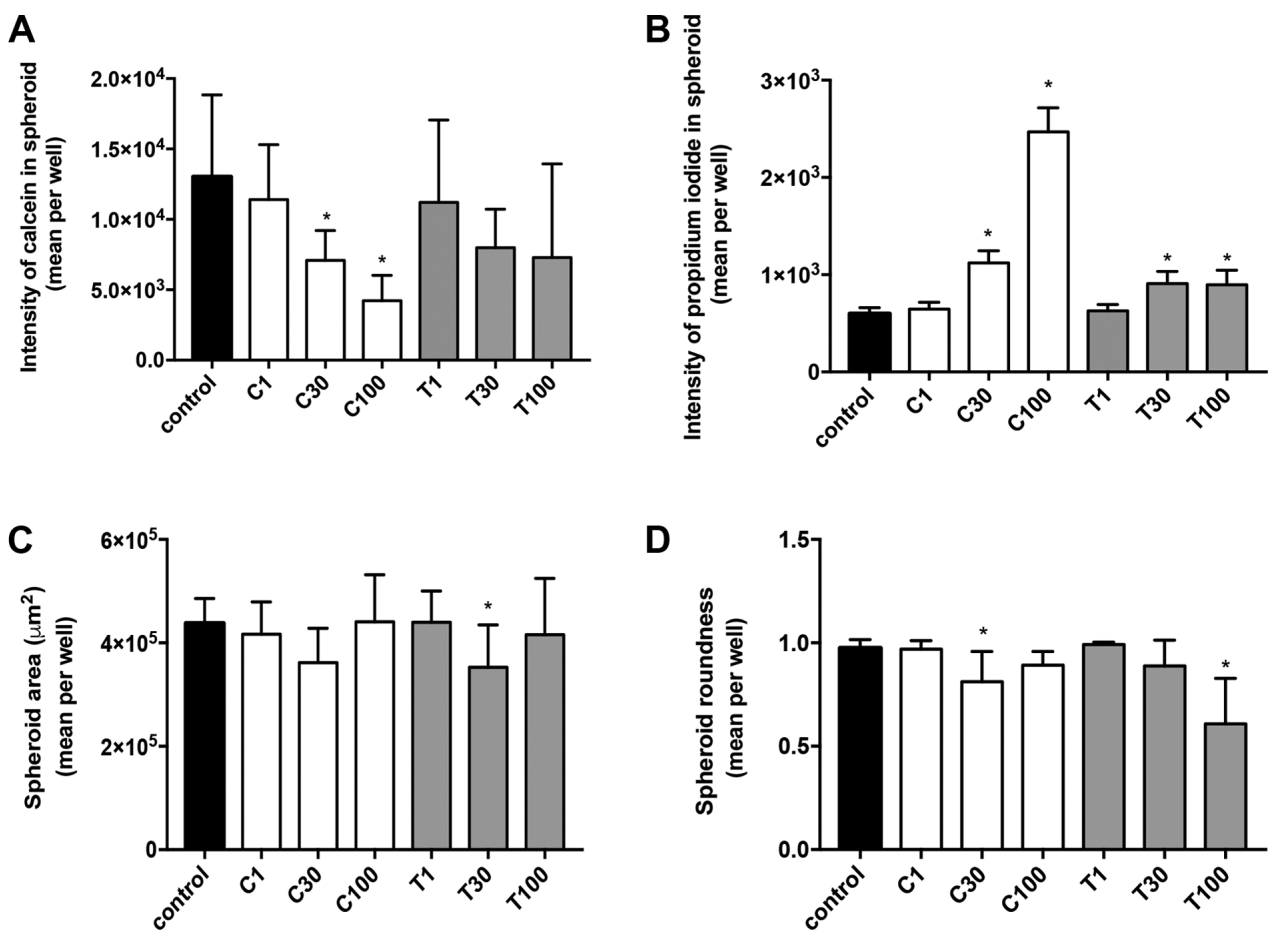

Figure 9. Fluorescence intensities and morphological examinations of spheroids of 3D MCF-7 cells treated with different concentrations of CEP or TET. Fluorescence intensity of (A) calcein and (B) propidium iodide in the spheroids. (C) Spheroid area and (D) spheroid roundness of 3D MCF-7 cells treated with CEP or TET. The intensity of calcein (cytoplasm) and propidium iodide (dead cells) fluorescence were detected after 15 min of incubation using an Operetta CLS (PerkinElmer, Inc.). The spheroid area and roundness were calculated using the same instrument. The data are shown as the mean + SD of 4 independent experiments. A roundness value of 1 corresponds to complete roundness, and lower values indicate the deformation of the spheroid. ${ }^{*} \mathrm{P}<0.05$ vs. control analyzed via one-way ANOVA and Dunnett's multiple comparisons test. C/CEP, cepharanthine; T/TET, tetrandrine. 


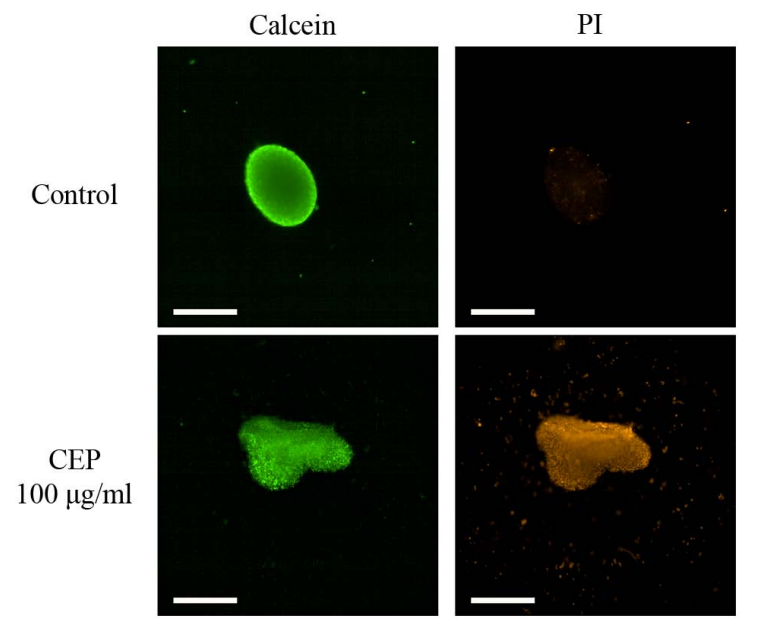

Figure 10. Photomicrographs of CEP-treated 3D MCF-7 spheroids stained with calcein or PI. MCF-7 spheroids were treated with $100 \mu \mathrm{g} / \mathrm{ml} \mathrm{CEP}$ and stained with calcein green or PI red, representing the cytoplasm or dead cells, respectively. Scale bar, $500 \mu \mathrm{m}$. CEP, cepharanthine; PI, propidium iodide.

Apoptosis. Cell apoptosis was examined by measuring the percentages of viable, early apoptotic and late apoptotic cells in both 2D-cultured cells and 3D-cultured spheroids. The flow cytometry plots for all cells with all treatment concentrations are shown in Figs. S3 and S4. For 2D-cultured MDA-MB-231 cells, there was a statistically significant greater difference in cell survival when $>10 \mu \mathrm{g} / \mathrm{ml}$ CEP was used compared with in the control $(\mathrm{P}<0.05$; Fig. 11A). Early apoptotic cells were significantly increased at $10 \mu \mathrm{g} / \mathrm{ml}$ CEP $(\mathrm{P}<0.05$; Fig. 11B), and CEP at $30 \mu \mathrm{g} / \mathrm{ml}$ significantly induced late apoptosis compared with in the control $(\mathrm{P}<0.05$; Fig. 11C). Compared with TET, CEP induced apoptosis of MDA-MB-231 cells at a high rate (Fig. 11A-C). By contrast, MCF-7 cells required high concentrations of CEP and TET to induce apoptosis (Fig. 11E-G). Using $30 \mu \mathrm{g} / \mathrm{ml}$ CEP or TET significantly decreased the number of viable cells compared with in the control $(\mathrm{P}<0.05$; Fig. 11E), but it did not influence the rate of early apoptotic cells in MCF-7 cells (Fig. 11F). Additionally, there were no significant differences compared with in the control group for the rate of late apoptotic cells, except with $30 \mu \mathrm{g} / \mathrm{ml}$ TET $(\mathrm{P}<0.05$; Fig. $11 \mathrm{G})$.

In MDA-MB-231 spheroids, the rate of early apoptotic cells increased after treatment with $10 \mu \mathrm{g} / \mathrm{ml} \mathrm{CEP}$ and TET compared with in the control (Fig. 12A and B). However, the drugs exhibited no significant effect on the rate of late apoptotic cells in MDA-MB-231 spheroids (Fig. 12C). Consequently, the viability of the MCF-7 spheroids seemed to be suppressed (Fig. 12E), but the percentage of early apoptotic cells among groups did not significantly change (Fig. 12F). Only $30 \mu \mathrm{g} / \mathrm{ml}$ TET significantly increased the rate of late apoptotic cells in MCF-7 spheroids $(\mathrm{P}<0.05$; Fig. 12G).

The percentages of viable, early apoptotic, late apoptotic and necrotic cells after treatment with CEP or TET in 2D or 3D cultures of MDA-MB-231 and MCF-7 cells are comparatively shown in Figs. 13 and 14, respectively. According to these summarized models, MDA-MB-231 2D cell cultures, compared with the $3 \mathrm{D}$ spheroids, appeared to be more sensitive to the apoptotic inducing effects of CEP and TET (Fig. 13). CEP and TET did not cause major necrosis in 2D- and 3D-cultured MDA-MB-231 and MCF-7 cells (Figs. 13 and 14).

\section{Discussion}

The present study demonstrated the antitumor effects of CEP and TET in human breast cancer monolayer cells and spheroids. Both drugs suppressed cell viability and induced apoptosis, and MDA-MB-231 cells exhibited a higher sensitivity to the suppressive effects of TET and CEP.

In the current study, the cell density in 2D and 3D cell culture systems was chosen as 10,000 and 20,000 cells/well, respectively, to compare the differences of CEP and TET. These numbers were selected based on the protocol for the CellCarrier Spheroid ULA 96-well microplates, which stated the maximum seeding density should be 40,000 cells/well. As shown in Table I, the $\mathrm{IC}_{50}$ values of CEP and TET on the viability of cells cultured in high cell numbers with the 2D method were higher compared with those in low cell numbers, and it was estimated that $3 \mathrm{D}$ spheroids require higher concentrations of each drug to decrease cell viability. Alternatively, if a high cell density was chosen for the 2D method, the control breast cancer cells would be confluent after incubation. Therefore, the cell densities in the present study used for the 2D and 3D cell culture systems were chosen as 10,000 and 20,000 cells/well, respectively, to compare the differences of the effect of CEP and TET between cells cultured in 2D and those cultured in $3 \mathrm{D}$.

The drug concentrations used in the present study were chosen based on a previous report demonstrating that CEP and TET caused apoptosis in glucocorticoid resistant human leukemia Jurkat $\mathrm{T}$ cells after $72 \mathrm{~h}$ of drug treatment, in which the $\mathrm{IC}_{50}$ values were $3.66 \pm 0.22 \mu \mathrm{M}$ for CEP and $3.98 \pm 0.05 \mu \mathrm{M}$ for TET (36). The units were converted to ' $\mu \mathrm{g} / \mathrm{ml}$ ' based on the molecular weights of the test compounds, giving a value of $\sim 2.5 \mu \mathrm{g} / \mathrm{ml}$. It was hypothesized that spheroids would require a higher concentration compared with 2D-cultured cells to induce apoptosis. Based on the aforementioned calculation and hypothesis, it was decided to use a drug concentration range between 0 and $100 \mu \mathrm{g} / \mathrm{ml}$. The present results indicated that 3D spheroids required higher concentrations to induce cell death compared with 2D monolayer cells.

Additionally, it was considered that the longer treatment period may improve the exposure to the drugs, since drugs require longer to penetrate enough into spheroids (35). Previous studies have evaluated the effects of drugs on the growth of MDA-MB-231 spheroids using a treatment period of $72 \mathrm{~h}(35,37)$. According to these studies, it was speculated that a treatment time of $72 \mathrm{~h}$ would also be appropriate for the present study. However, studying the effects on 3D spheroids may require a longer treatment period in order to understand drug metabolism or drug distribution, which should be investigated in future studies.

Since there are no available targeted therapy options for TNBC, the standard treatment regimen remains chemotherapy (38). Notably, TNBC generally has improved responses to chemotherapy compared with other subtypes (38). However, patients without complete response account for $\sim 80 \%$ of TNBC cases (38), and therefore, the development of novel strategies or drugs is essential for the treatment of TNBC. The present 

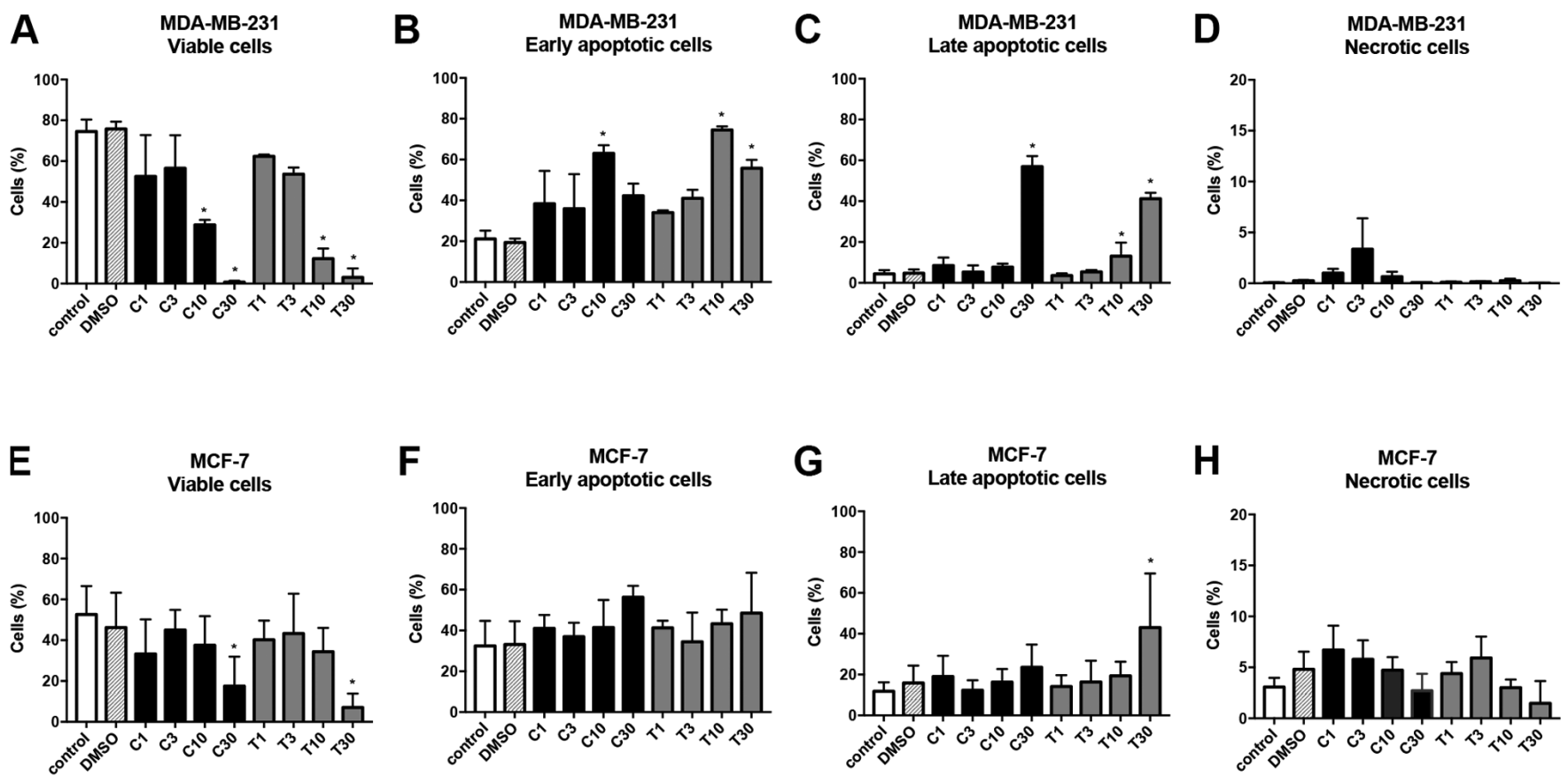

I

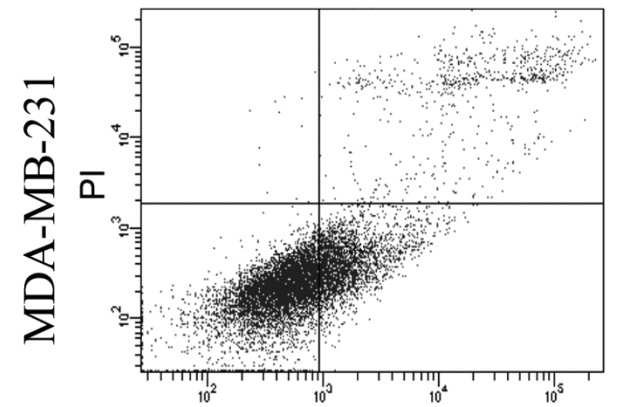

FITC

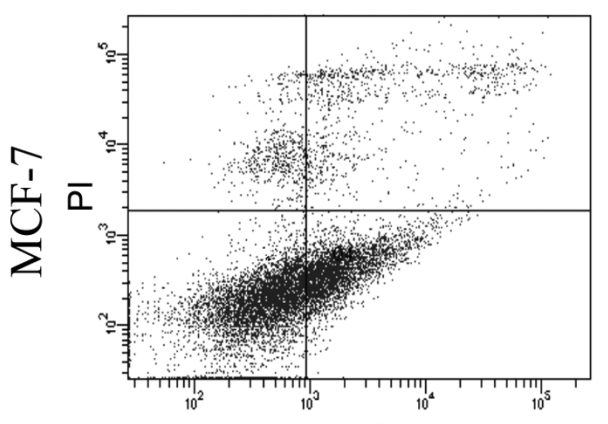

FITC
C30

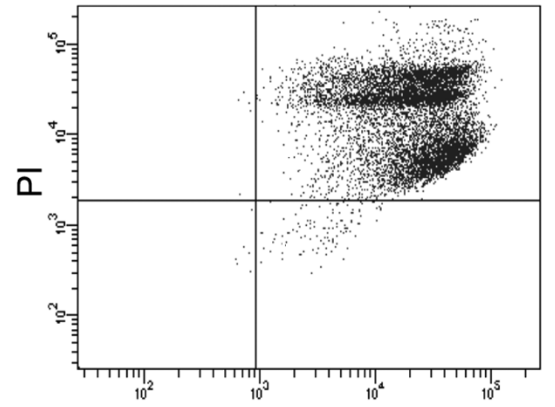

FITC

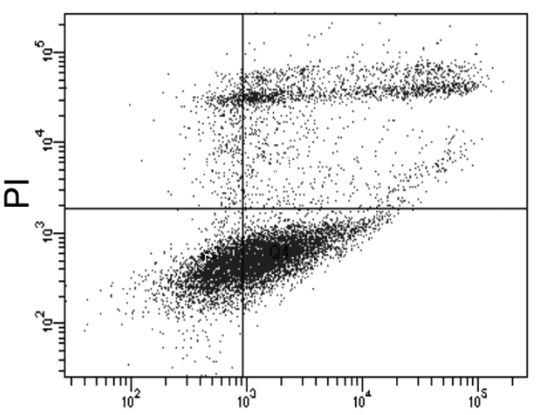

FITC
$\mathrm{T} 30$

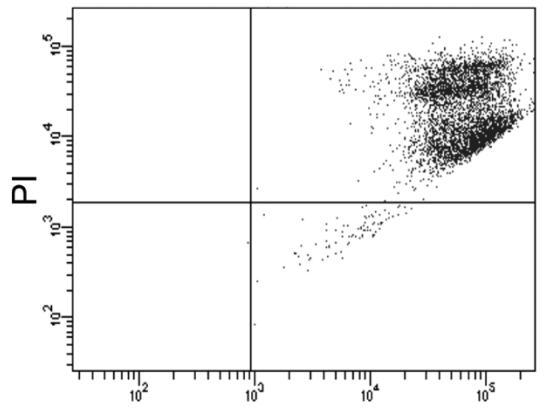

FITC

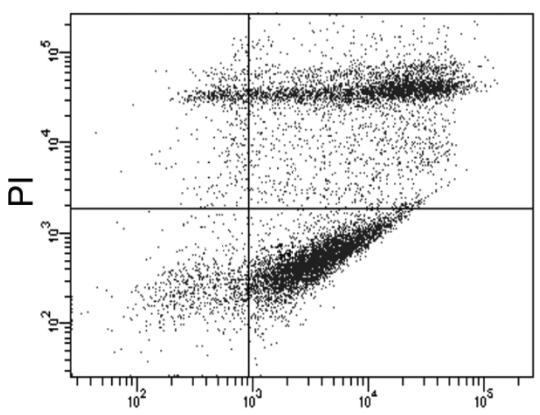

FITC

Figure 11. Effects of CEP and TET on percentages of viable, early apoptotic, late apoptotic and necrotic cells of MDA-MB-231 and MCF-7 monolayer cells. After treatment with different concentrations of CEP or TET, 2D monolayer MDA-MB-231 were stained with Annexin V-FITC and PI to identify (A) viable, (B) early apoptotic, (C) late apoptotic and (D) necrotic cells. Similarly, MCF-7 cells were stained with Annexin V-FITC and PI to identify (E) viable, (F) early apoptotic, $(\mathrm{G})$ late apoptotic and $(\mathrm{H})$ necrotic cells. Data are shown as the mean $+\mathrm{SD}$ of 4 independent experiments. (I) Cells treated with $30 \mu \mathrm{g} / \mathrm{ml} \mathrm{CEP}$ or TET were classified into four groups based on different quadrants: Viable cells (bottom left), early apoptotic cells (bottom right), late apoptotic cells (upper right) and necrotic cells (upper left) using flow cytometry. ${ }^{*} \mathrm{P}<0.05$ vs. control analyzed via one-way ANOVA and Dunnett's multiple comparisons test. $\mathrm{C} / \mathrm{CEP}$, cepharanthine; T/TET, tetrandrine; PI, propidium iodide.

study revealed that the TNBC MDA-MB-231 cells were more sensitive compared with MCF-7 cells to the cytotoxic effects of TET and CEP in the 3D culture system. Other types of breast cancer cells, such as HER2 ${ }^{+}$breast cancer cells, or cancer cells modeling other diseases were not used in the current study to evaluate the efficacy of TET and CEP, and therefore, the present results may only reflect MCF-7 and MDA-MB-231 cell lines. However, these results demonstrated the potential for CEP and TET to be used as novel therapeutic strategies for breast cancer. 
A
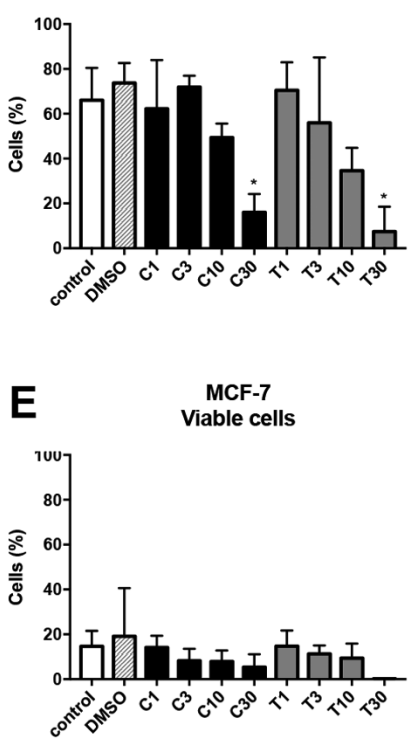

B
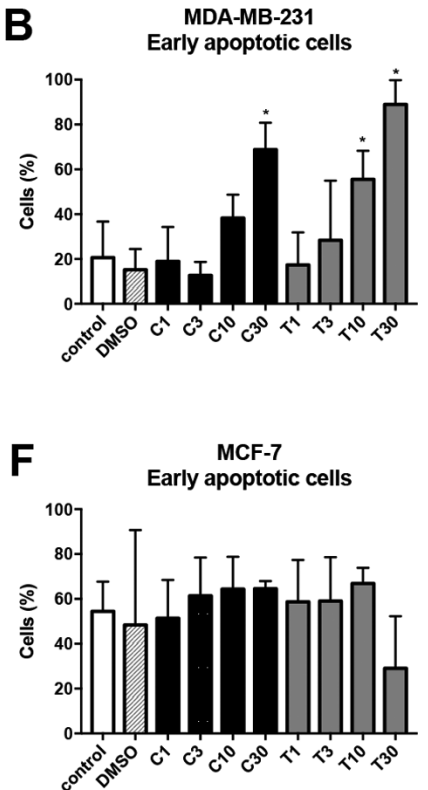

C
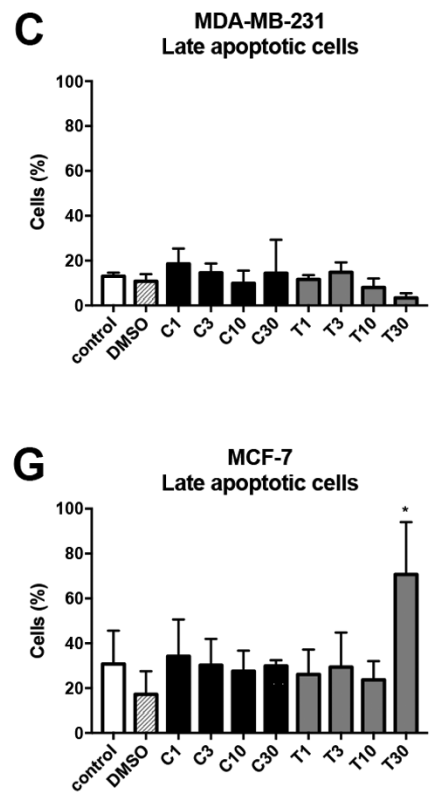
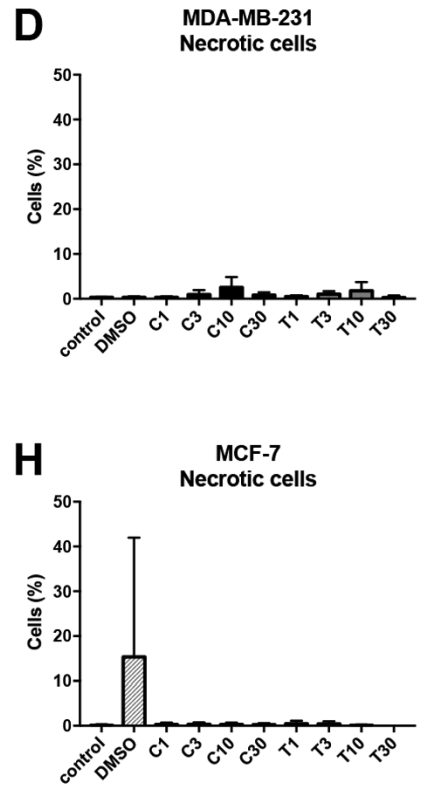

I

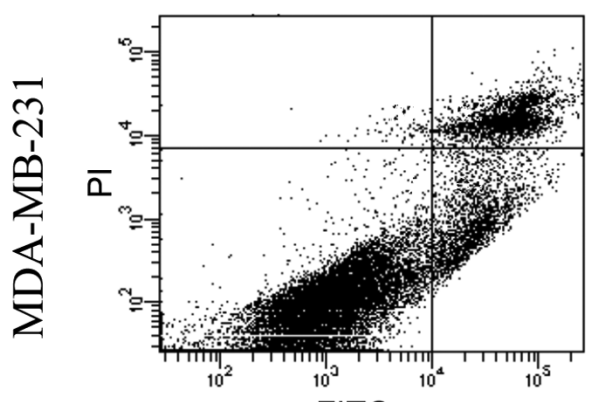

FITC

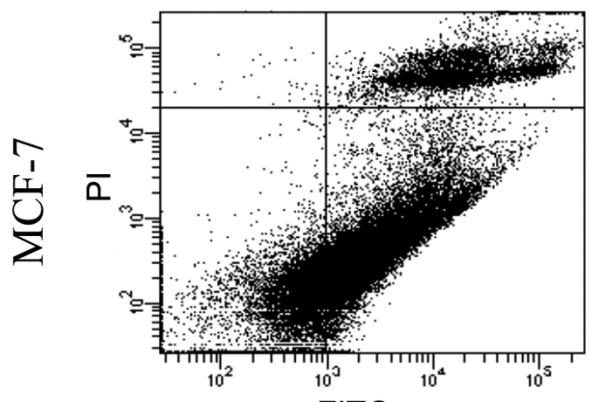

FITC
$\mathrm{C} 30$

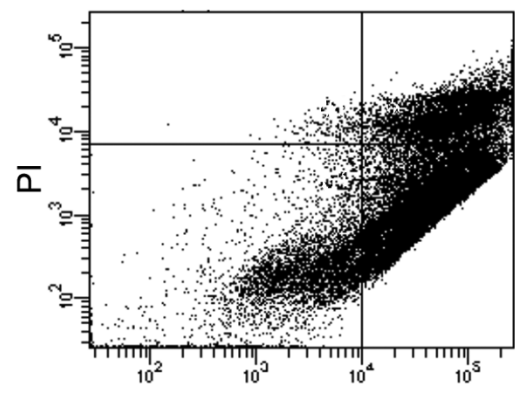

FITC

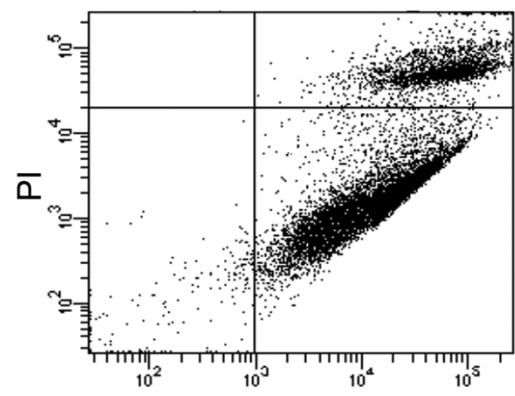

FITC
T30

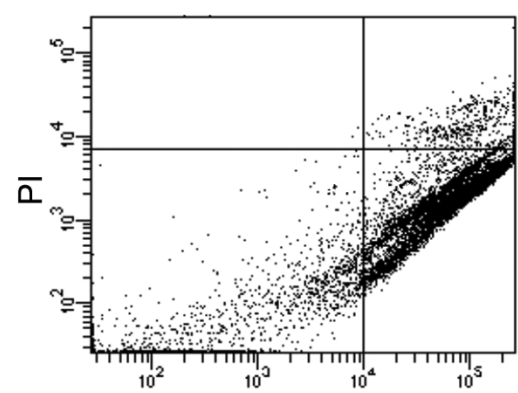

FITC

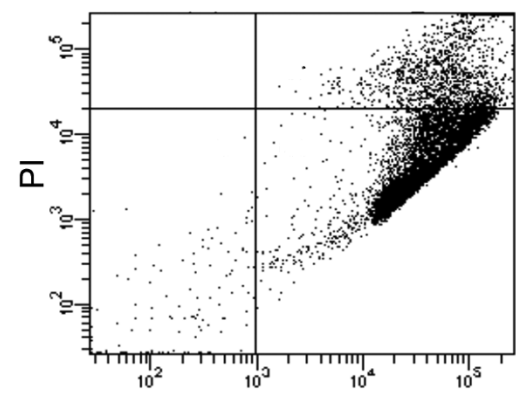

FITC

Figure 12. Effects of CEP and TET on percentages of viable, early apoptotic, late apoptotic and necrotic cells of MDA-MB-231 and MCF-7 spheroids. After the treatment with different concentrations of CEP or TET, 3D MDA-MB-231 spheroids were stained with Annexin V-FITC and PI to identify (A) viable, (B) early apoptotic, (C) late apoptotic and (D) necrotic cells. Similarly, MCF-7 spheroids were stained with Annexin V-FITC and PI to identify (E) viable, (F) early apoptotic, (G) late apoptotic and (H) necrotic cells. The data are shown as the mean + SD of 4 independent experiments. (I) Cells treated with $30 \mu \mathrm{g} / \mathrm{ml}$ CEP or TET were classified into four groups based on different quadrants: Viable cells (bottom left), early apoptotic cells (bottom right), late apoptotic cells (upper right) and necrotic cells (upper left) using flow cytometry. ${ }^{~} \mathrm{P}<0.05$ vs. control analyzed via one-way ANOVA and Dunnett's multiple comparisons test. $\mathrm{C} / \mathrm{CEP}$, cepharanthine; T/TET, tetrandrine; PI, propidium iodide.

TET has been demonstrated to have positive therapeutic effects on cardiovascular disease, hypertension, silicosis and autoimmune diseases (39). In addition, TET is already used clinically for the treatment of some types of cancer, such as acute myelogenous leukemia and advanced non-small cell lung cancer, in China $(18,19)$. Notably, the present study demonstrated that CEP had stronger effects on MDA-MB-231 and MCF-7 cells compared with TET, in a concentration-dependent manner. This suggested that CEP may potentially be used as an anticancer drug for breast cancer and may be an alternative treatment of TET.

The present study evaluated the morphological changes of the cytoplasm, nucleus and nucleic acid of dead cells in order to examine the cell toxicity caused by CEP and TET. Non-fluorescent calcein crosses the membrane of living cells easily and is hydrolyzed in the cytoplasm 
CEP

2D

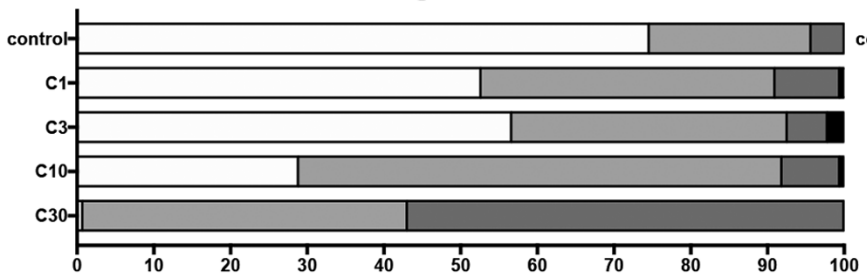

TET

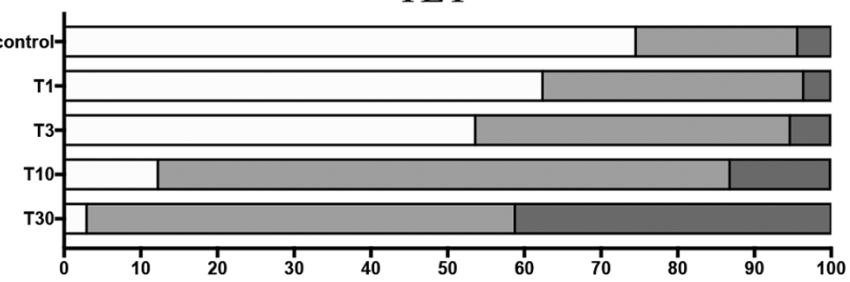

$3 \mathrm{D}$
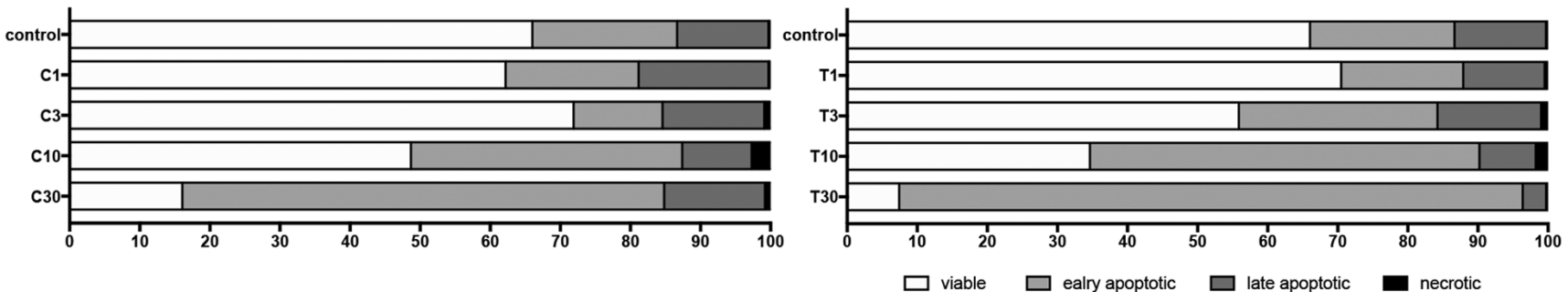

Figure 13. Comparison of the percentages of viable, early apoptotic, late apoptotic and necrotic cells in 2D monolayer or 3D spheroids MDA-MB-231 cells treated with different concentrations of CEP or TET. 2D- or 3D-cultured MDA-MB-231 cells treated with CEP or TET were categorized into viable (white), early apoptotic (light grey), late apoptotic (dark grey) and necrotic (black) cells after staining with Annexin V and PI analyzed via flow cytometry. C/CEP, cepharanthine; T/TET, tetrandrine.

CEP

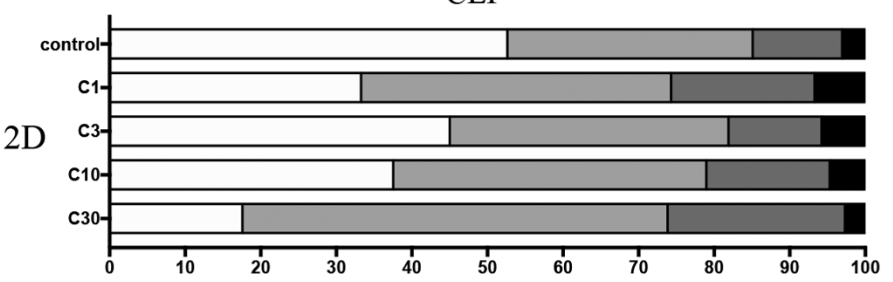

$3 \mathrm{D}$

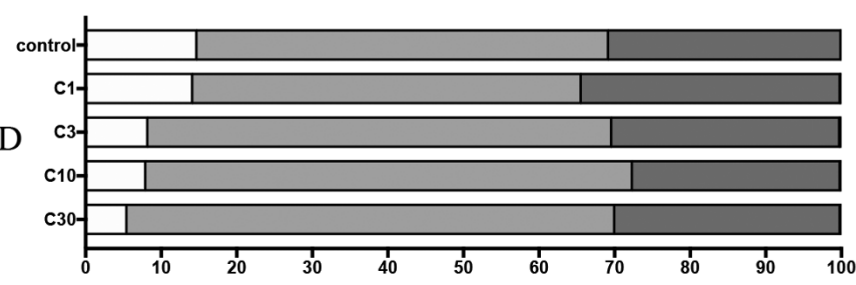

TET
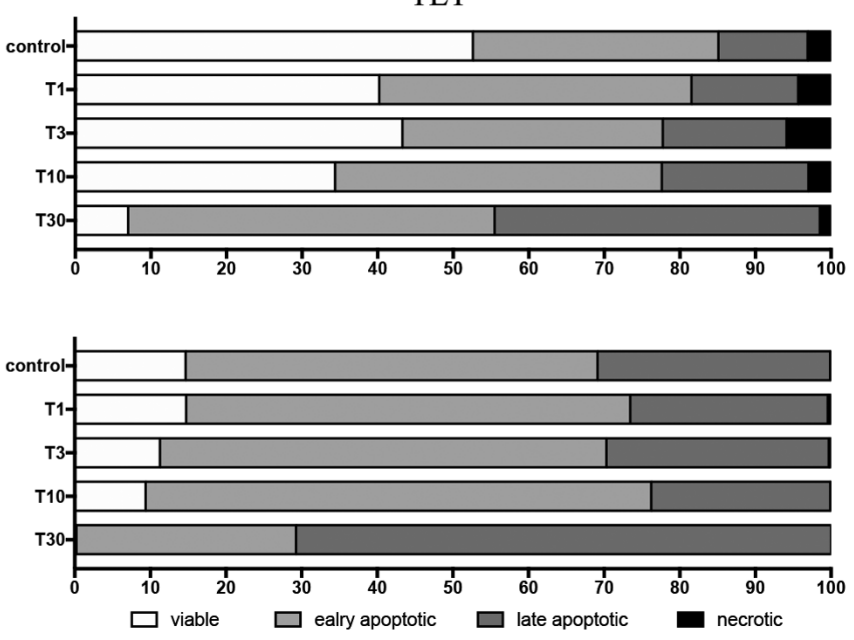

Figure 14. Comparison of the percentages of viable, early apoptotic, late apoptotic and necrotic cells in 2D monolayer or 3D spheroids MCF-7 cells treated with different concentrations of CEP or TET. 2D- or 3D-cultured MCF-7 cells treated with CEP or TET were categorized into viable (white), early apoptotic (light grey), late apoptotic (dark grey) and necrotic (black) cells after staining with Annexin V and PI analyzed via flow cytometry. C/CEP, cepharanthine; T/TET, tetrandrine.

by intracellular esterases to a membrane-impermeable green-fluorescent calcein (40). Generally, PI does not penetrate the cell membrane of living cells, but it only enters into dead cells and then intercalates with DNA in the nucleus to emit red fluorescence (41). The strength of the fluorescence indicates more chromatin aggregation, which is a degree of increased apoptosis (41). In the present study, both CEP and TET induced apoptosis in MDA-MB-231 and MCF-7 cell lines in a dose-dependent manner. Additionally, CEP decreased the cytoplasmic space, increased chromatin condensation and increased the number of dead cells in a dose-dependent manner. The current results suggested that CEP may be more potent at inducing cell death compared with TET, which is already used for cancer treatment $(18,19)$. Notably, a previous report demonstrated that TET and CEP induced apoptosis of leukemia Jurkat $\mathrm{T}$ cells in vitro, and the important markers of apoptosis, p53 and Bax, were both upregulated via treatment with TET and CEP (36). While the mechanism remains unclear, this apoptotic effect may be due to the methoxy group of TET, which is likely involved with the blockade of voltage-operated $\mathrm{Ca}^{2+}$ entry, and since CEP has the same methoxy group, it may behave similarly (42). Therefore, further studies are required to understand the detailed underlying apoptotic mechanism.

The present study evaluated the effects of TET and CEP on breast cancer cell lines using models of 2D monolayer and 3D spheroids. Previously, numerous types of in vitro 3D culture systems have been developed to mimic the in vivo growth environment of cancer (43). These cancer 3D culture systems aim to preserve and improve the 
biological characteristics of the original tumor microenvironment compared with conventional 2D monolayer culture systems (25). Some 3D culture systems have been successful for screening out the chemotherapeutic drug sensitivities of cancer cells (44). However, 2D culture systems have been used to compare the results conducted by $2 \mathrm{D}$ and 3D systems (45). The present experiments demonstrated that 3D spheroids had a higher sensitivity to CEP compared with TET. Furthermore, CEP decreased the volume of the cytoplasm and increased apoptosis. As demonstrated by the apoptosis assay using flow cytometry, the viability of MDA-MB-231 spheroids was markedly suppressed by CEP and TET compared with that of MCF-7 spheroids. However, compared with 2D monolayer cells, 3D spheroids exhibited a lower response to the suppressive effects of CEP and TET, especially in MCF-7 cells. Imamura et al (26) reported that the central part of spheroids of breast cancer cells formed in 3D culture becomes hypoxic, which may cause dormancy of tumor cells in the $\mathrm{G}_{0}$ phase, downregulating the expression levels of caspase-3. This suggests that higher concentrations of CEP are required to have an effect on cancer spheroids. Furthermore, a previous study reported that a conventional anticancer medicine, cisplatin, in combination with CEP increased the efficacy of the conventional drug in esophageal squamous cell carcinoma and decreased its side effects on gut microorganisms and intestinal mucosal immunity (46). Detailed analysis of the effect of CEP combined with cisplatin against breast cancer cells is warranted in future studies.

CEP was approved in 1969 and has been used for a long period of time in Japan; it has been used for patients with alopecia areata and leukopenia caused by radiation therapy, and it has been demonstrated to be safe and effective in Japan (20). Therefore, CEP would be practical, safe and easier to be approved for use in patients with cancer after additional clinical research and trials. Additionally, there are several formulations of CEP, including tablets, powder and injection (20).

In conclusion, in the present study CEP and TET demonstrated toxicity in MDA-MB-231 and MCF-7 monolayer cells, as well as in spheroids of these cell lines, observed via decreases in the cytoplasm and chromatin aggregation. Although the current results suggested that the cytotoxicity of CEP and TET may be associated with the induction of apoptosis, the exact mechanism is not completely understood and requires further investigation. CEP and TET caused cytotoxicity in spheroids of MDA-MB-231 and MCF-7 cells, with MDA-MB-231 cells exhibiting higher sensitivity to these compounds. CEP induced stronger apoptosis and spheroid cytotoxicity than TET. Therefore, the present results suggested that CEP may have a stronger antitumor activity against TNBC spheroids compared with TET.

\section{Acknowledgements}

The authors would like to thank Dr Anh Tan Truong (University of Southern California, Los Angeles, CA, USA) for the constructive comments and proofreading of the manuscript, and Mrs. Atsuko Kiyomi for figure formatting and editing.

\section{Funding}

Funding was provided by the Tokyo University of Pharmacy and Life Sciences.

\section{Availability of data and materials}

All data generated or analyzed during this study are included in this published article.

\section{Authors' contributions}

AK, BY, TH and MS designed the study. AK, RM, JM and KY conducted the experiments and analyzed the data. AK, SI, BY, $\mathrm{TH}$ and MS interpreted the data. AK wrote the manuscript. All authors read and approved the final manuscript.

\section{Ethics approval and consent to participate}

Not applicable.

\section{Patient consent for publication}

Not applicable.

\section{Competing interests}

The authors declare that they have no competing interests.

\section{References}

1. Tao Z, Shi A, Lu C, Song T, Zhang Z and Zhao J: Breast cancer: Epidemiology and etiology. Cell Biochem Biophys 72: 333-338, 2015.

2. Coughlin S: Epidemiology of breast cancer in women. Adv Exp Med Biol 1152: 9-29, 2019.

3. Winters S, Martin C, Murphy D and Shokar N: Breast cancer epidemiology, prevention, and screening. Prog Mol Biol Transl Sci 151: 1-32, 2017.

4. Harbeck N and Gnant M: Breast cancer. Lancet 389: 1134-1150, 2017.

5. Carey L, Winer E, Viale G, Cameron D and Gianni L: Triple-negative breast cancer: Disease entity or title of convenience? Nat Rev Clin Oncol 7: 683-692, 2010.

6. Liedtke C, Mazouni C, Hess K, André F, Tordai A, Mejia J, Symmans WF, Gonzalez-Angulo A, Hennessy B, Green M, et al: Response to neoadjuvant therapy and long-term survival in patients with triple-negative breast cancer. J Clin Oncol 26: 1275-1281, 2008.

7. Rakha EA, El-Sayed ME, Green AR, Lee AH, Robertson JF and Ellis IO: Prognostic markers in triple-negative breast cancer. Cancer 109: 25-32, 2007.

8. Denkert C, Liedtke C, Tutt A and von Minckwitz G: Molecular alterations in triple-negative breast cancer-the road to new treatment strategies. Lancet 389: 2430-2442, 2017.

9. Thomford NE, Senthebane DA, Rowe A, Munro D, Seele P, Maroyi A and Dzobo K: Natural products for drug discovery in the 21 st century: Innovations for novel drug discovery. Int J Mol Sci 19: 1578, 2018.

10. Harvey AL: Natural products in drug discovery. Drug Discov Today 13: 894-901, 2008.

11. Chen Y: Potential role of tetrandrine in cancer therapy. Acta Pharmacol Sin 23: 1102-1106, 2002.

12. Liu T, Liu X and Li W: Tetrandrine, a Chinese plant-derived alkaloid, is a potential candidate for cancer chemotherapy. Oncotarget 7: 40800-40815, 2016.

13. Liu B, Wang T, Qian X, Liu G, Yu L and Ding Y: Anticancer effect of tetrandrine on primary cancer cells isolated from ascites and pleural fluids. Cancer Lett 268: 166-175, 2008. 
14. Lu Y, Li F, Xu T and Sun J: Tetrandrine prevents multidrug resistance in the osteosarcoma cell line, U-2OS, by preventing Pgp overexpression through the inhibition of $\mathrm{NF}-\kappa \mathrm{B}$ signaling. Int $\mathrm{J}$ Mol Med 39: 993-1000, 2017.

15. Zhu R, Liu T, Tan Z, Wu X, Li M, Jiang L, Bao R, Shu Y, Lu A and Liu Y: Tetrandrine induces apoptosis in gallbladder carcinoma in vitro. Int J Clin Pharmacol Ther 52: 900-905, 2014.

16. Sun XC, Cheng HY, Deng YX, Shao RG and Ma J: Tetrandrine: A potent abrogator of $\mathrm{G} 2$ checkpoint function in tumor cells and its mechanism. Biomed Environ Sci 20: 495-501, 2007.

17. Qiu W, Zhang AL and Tian Y: Tetrandrine triggers an alternative autophagy in DU145 cells. Oncol Lett 13: 3734-3738, 2017.

18. Xu WL, Shen HL, Ao ZF, Chen BA, Xia W, Gao F and Zhang YN: Combination of tetrandrine as a potential-reversing agent with daunorubicin, etoposide and cytarabine for the treatment of refractory and relapsed acute myelogenous leukemia. Leuk Res 30: 407-413, 2006.

19. Liu W, Zhang J, Ying C, Wang Q, Yan C, Jingyue Y, Zhaocai Y, Yan X, Heng-jun S and Lin J: Tetrandrine combined with gemcitabine and cisplatin for patients with advanced non-small cell lung cancer improve efficacy. Int J Biomed Sci 8: 28-35, 2012.

20. Bailly C: Cepharanthine: An update of its mode of action, pharmacological properties and medical applications. Phytomedicine 62: 152956, 2019.

21. Asaumi J, Nishikawa K, Matsuoka H, Iwata M, Kawasaki S, Hiraki Y and Nishijima K: Direct antitumor effect of cepharanthin and combined effect with adriamycin against Ehrlich ascites tumor in mice. Anticancer Res 15: 67-70, 1995

22. Ono M and Tanaka N: Positive interaction of bisbenzylisoquinoline alkaloid, cepharanthin, with vinca alkaloid agents against human tumors. In Vivo 11: 233-241, 1997.

23. Rosso F, Giordano A, Barbarisi M and Barbarisi A: From cell-ECM interactions to tissue engineering. J Cell Physiol 199: 174-180, 2004

24. Ryu N, Lee S and Park H: Spheroid culture system methods and applications for mesenchymal stem cells. Cells 8: 1620 2019.

25. Breslin S and O'Driscoll L: The relevance of using 3D cell cultures, in addition to $2 \mathrm{D}$ monolayer cultures, when evaluating breast cancer drug sensitivity and resistance. Oncotarget 7 : 45745-45756, 2016.

26. Imamura Y, Mukohara T, Shimono Y, Funakoshi Y, Chayahara N, Toyoda M, Kiyota N, Takao S, Kono S, Nakatsura T and Minami H: Comparison of 2D- and 3D-culture models as drug-testing platforms in breast cancer. Oncol Rep 33: 1837-1843, 2015.

27. Moscona A: Rotation-mediated histogenetic aggregation of dissociated cells. A quantifiable approach to cell interactions in vitro. Exp Cell Res 22: 455-475, 1961.

28. O'Keane JC, Kupchik HZ, Schroy PC, Andry CD, Collins E and O'Brien MJ: A three-dimensional system for long-term culture of human colorectal adenomas. Am J Pathol 137: 1539-1547, 1990.

29. Carlsson J, Nilsson K, Westermark B, Pontén J, Sundström C, Larsson E, Bergh J, Påhlman S, Busch C and Collins VP: Formation and growth of multicellular spheroids of human origin. Int J Cancer 31: 523-533, 1983.

30. Kleinman HK, McGarvey ML, Hassell JR, Star VL, Cannon FB, Laurie GW and Martin GR: Basement membrane complexes with biological activity. Biochemistry 25: 312-318, 1986.

31. Lawler EM, Miller FR and Heppner GH: Significance of three-dimensional growth patterns of mammary tissues in collagen gels. In Vitro 19: 600-610, 1983.
32. Bresciani G, Hofland LJ, Dogan F, Giamas G, Gagliano T and Zatelli MC: Evaluation of spheroid 3D culture methods to study a pancreatic neuroendocrine neoplasm cell line. Front Endocrinol (Lausanne) 10: 682, 2019.

33. Nath $\mathrm{S}$ and Devi G: Three-dimensional culture systems in cancer research: Focus on tumor spheroid model. Pharmacol Ther 163 94-108, 2016

34. Kelm JM, Timmins NE, Brown CJ, Fussenegger $M$ and Nielsen LK: Method for generation of homogeneous multicellular tumor spheroids applicable to a wide variety of cell types. Biotechnol Bioeng 83: 173-180, 2003.

35. Vinci M, Gowan S, Boxall F, Patterson L, Zimmermann M, Court W, Lomas C, Mendiola M, Hardisson D and Eccles SA: Advances in establishment and analysis of three-dimensional tumor spheroid-based functional assays for target validation and drug evaluation. BMC Biol 10: 29, 2012.

36. Xu W, Wang X, Tu Y, Masaki H, Tanaka S, Onda K, Sugiyama K, Yamada $\mathrm{H}$ and Hirano T: Tetrandrine and cepharanthine induce apoptosis through caspase cascade regulation, cell cycle arrest, MAPK activation and PI3K/Akt/mTOR signal modification in glucocorticoid resistant human leukemia Jurkat T cells. Chem Biol Interact 130: 108726, 2019.

37. Nigjeh SE, Yeap SK, Nordin N, Kamalideghan B, Ky H and Rosli R: Citral induced apoptosis in MDA-MB-231 spheroid cells. BMC Complement Altern Med 18: 56, 2018.

38. Jhan JR and Andrechek ER: Triple-negative breast cancer and the potential for targeted therapy. Pharmacogenomics 18: $1595-1609,2017$

39. Bhagya $\mathrm{N}$ and Chandrashekar KR: Tetrandrine-A molecule of wide bioactivity. Phytochemistry 125: 5-13, 2016.

40. Gatti R, Belletti S, Orlandini G, Bussolati O, Dall'Asta V and Gazzola GC: Comparison of annexin V and calcein-AM as early vital markers of apoptosis in adherent cells by confocal laser microscopy. J Histochem Cytochem 46: 895-900, 1998.

41. Basmaciyan L, Azas N and Casanova M: Calcein+/PI-as an early apoptotic feature in Leishmania. PLoS One 12: e0187756, 2017.

42. Leung YM, Berdik M, Kwan CY and Loh TT: Effects of tetrandrine and closely related bis-benzylisoquinoline derivatives on cytosolic $\mathrm{Ca}^{2+}$ in human leukemic HL-60 cells: A structure-activity relationship study. Clin Exp Pharmacol Physiol 23: 653-659, 1996.

43. Kunz-Schughart L, Freyer J, Hofstaedter F and Ebner R: The use of 3-D cultures for high-throughput screening: The multicellular spheroid model. J Biomol Screen 9: 273-285, 2004.

44. Kiyomi A, Makita M, Ozeki T, Li N, Satomura A, Tanaka S, Onda K, Sugiyama K, Iwase T and Hirano T: Characterization and clinical implication of Th1/Th2/Th17 cytokines produced from three-dimensionally cultured tumor tissues resected from breast cancer patients. Transl Oncol 8: 318-326, 2015.

45. Jo Y, Choi N, Kim K, Koo HJ, Choi J and Kim HN: Chemoresistance of cancer cells: Requirements of tumor microenvironment-mimicking in vitro models in anti-cancer drug development. Theranostics 8: 5259-5275, 2018.

46. Zhou P, Li Z, Xu D, Wang Y, Bai Q, Feng Y, Su G, Chen P, Wang Y, Liu H, et al: Cepharanthine hydrochloride improves cisplatin chemotherapy and enhances immunity by regulating intestinal microbes in mice. Front Cell Infect Microbiol 9: 225, 2019. International (CC BY-NC-ND 4.0) License. 